


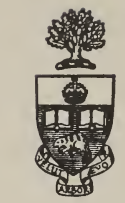

Library

of the

University of Toronto 



\title{
BOOKS PUBLISHED
}

BY

\section{WILLIAM BLACKWOOD AND SONS,}

\author{
EDINBURGH AND LONDON.
}

\section{T II E S U B A L T E R N.}

A New Edition, Revised by the Author.

PRICE HALF-A-CROWN.

\section{THE LIFE OF MANSIE WAUCH, \\ TAILOR IN DALKEITH. \\ WRITTEN BY HIMSELF. \\ A New Edition, in foolscap octavo, \\ ,PRICE HALF-A-CROWN,}

\section{LIGHTS AND SHADOWS OF SCOT'TISH LIFE.}

A NEW EDITION, PRICE HALF-A-CROWN,

Handsomely bound in cloth, gilt edges, $3 \mathrm{~s}$. 6d. : in morocco elegant, 0s, 6d.

"What child will not hang over tho Tales of the Covenanters, in Lights and Shadows of Scottish Life?

"We have already said a word or two on this delightful volume. The work of one of the highest and most amiable of contemporary minds-a genius which shines with equal felicity in the tender and the humorous." -Quarterly Review.

\section{TRIALS OF MARGARET LYNDSAY.}

By tho same Author,

A New Edition, in foolseap octavo,

PRICR HALF-A-CROWN. 


\section{THE HISTORY OF EUROPE}

DURING THE FRENCH REVOLUTION.

By ARCHIBALD ALISON, F.R.S.

$A$ New Edition, revised and greatly enlarged, in 10 vols. $8 \mathrm{vo}$, price $67,15 \mathrm{~s}$.

"After a full examination, we do not hesitate to say, that this is the most complete and honest history of the French Revolution which has as yet appeared, either in England or France. Certainly, no work by a British pen deserves to be compared with it; and we think every reader will accord it the preference, in point of fulness and impartiality, over the early narratives of the French Royalists, Bertrand de Molleville, Lacretelle, and others, and the more recent and popular works of Mignet and Thiers."-North American Review, 1843.

\section{THE RECREATIONS OF CHRISTOPHER NORTH.}

In three vols. post octavo, price $f 1,11$ s. $6 \mathrm{~d}$.

Contents :-Volume I. Christopher in his Sporting Jacket-A Tale of Expiation-Morning Monologue-The Field of Flowers-Cottages -An Hour's talk about Poetry-Inch Cruin-A Day at Winder. mere.

Voudme II. The Moors-Highland Snow-Storm-The Holy ChildOur Parish-May-Day-Sacred Poetry.

Voldme III. Christopher in his Aviary-Dr Kitchiner-Soliloquy on the Seasons-A Few Words on Thomson-The Snowball Bicker of Pedmont-Christmas Dreams-Our Winter Quarters-Stroll to Grassmere-L'Envoy.

"Delightful volumes-full of fun and fervour, power and pathos-of deep feeling and light-hearted gaiety-of impassioned language, rolling along in the strength and majesty of genuine eloquence-and of familiar gossip, tripping it lightly over the merrier pages."-Scotsman.

\section{MEN AND MANNERS IN AMERICA.}

\section{BY THE AUTHOR OF “CYRIL THORNTON."}

A NEW EDITION.

With a Portrait of the Author, and Letters written by him during his Journey through the United States.

In One Volume, Small Octavo, price 7s. 6d.

" Though many excellent volumes have since been published, not one has superseded it as a standard and safe authority. Other travellers have confirmed its accuracy, without adding much to its information * * * But this edition has another advantage. It is enriched with the private letters he wrote to his friends from America, in which his first impressions are recorded without concealment."-Britannia. 


\title{
A NEW EDITION OF \\ TEN THOUSAND A A-YEAR.
}

\author{
By SAMUEL WARREN, F.R.S.
}

Author of "The Diary of a Late Physician."

SECOND EDITION, CAREFULLY REVISED, WITH OCCASIONAL NOTES AND

ILLUSTRATIONS.

In Three Volumes, Foolscap Octavo, Price 18s.

"A remarkable novel."-" "Superior to any novel of actual life recently produced in this country."-Quarterly Review.

"The characters are excellent, some of them equal to the highest efforts of the highest masters; the insight into motives is searching; the scenes display a power of reproducing on paper what experience has taught; some of the incidents are novel, startling, and of surprising power."-Times.

\section{PASSAGES}

\section{FROM THE}

\section{DIARY OF A LATE PHYSICIAN.}

By the Same Author.

Complete in Two Volumes, uniform with the above, price $12 \mathrm{~s}$.

"What is nearest us touches us most. The passions rise higher at domestic than at imperial tragedies."-Dr. Johnson.

"They leave on them the undoubted stamp of genuineness; and the reflecting reader must be convinced, by the many characteristic touches with which most of them abound, that these narratives are at least founded upontruth; he will further feel persuaded that facts-facts witnessed by the Author-are related."-German Translator.

\section{THE HERETIC;}

\section{TRANSLATED FROM THE RUSSIAN OF LAJETCHNIKOFF.}

By THOMAS B. SHAW, of Cambridge

Adjunct Professor of English Literature in the Imperial Lyceum of Tzarskoe Selo.

In Three Vols., price $£ 1,11$ s. $6 \mathrm{~d}$

" The novel of 'The Heretic,' by Lajétchnikoff, has, we are glad to see, been well translated, and has attracted general attention in this country."Edinburgh Review.

"A Riussian novel in a graceful English dress, is an acceptable novelty, and as such we cordially recommend to public favour Mr Shaw's translation of M. Lajétchnikoft"s last work, "The Heretic." --Atlas. 


\section{THE WORKS OF MRS HEMANS,}

A COMPLETE AND UNIFORM EDITION.

WITH A MEMOIR BY HER SISTER.

In Seven Volumes, Foolscap Octavo, price $£ 1,15 \mathrm{~s}$, neatly bound in cloth, with Portraits and Vignettes, or $\mathrm{f3}, 3 \mathrm{~s}$. in morocco.

The following are published separately, neatly bound in cloth lettered, with Vignette Titles, price $5 \mathrm{~s}$. each, or elegantly bound in morocco, 9 s. :-

I. MEMOIR OF MRS HEMANS.

II. TALES AND HISTORIC SCENES.

III. THE SIEGE OF VALENCIA.

IV. THE FOREST SANCTUARY.

V. RECORDS OF WOMAN.

VI. SONGS OF THE AFFECTIONS.

VII. SONGS AND LYRICS.

\section{MRS SOUTHEY'S (CAROLINE BOWLES) WORKS.}

Uniformly Printed, in small octavo, neatly bound in cloth.

I.

Complete in one volume, price 7s. 6d.,

CHAPTERS ON CHURCHYARDS.

A NEW EDITION.

II.

SOLITARY HOURS.

A New Edition. Price 5s.

III.

THE BIRTHDAY AND OTHER POEMS.

Price 7s.

"We do not remember any recent author whose poetry is so unmixedly native; and this English complexion constitutes one of its characteristic charms. No purer models of our genuine home feeling and language could be placed in a young foreigner's hands than Mrs Southey's Works. Moreover her versification, especially in her two later volumes, is not only gener. ally correct, but, in several instances, of very great beauty and perfection. In her latest poem, 'The Birthday,' she has attained to a still higher excellence of style."-Quarterly Review. 


\title{
THE COURSE OF TIME,
}

\section{A POEM IN TEN BOOKS.}

By ROBERT POLLOK, M.A.

A New Edition (being the Sixteenth,) with Vignette Title and Portrait engraved by Robinson.

In small octavo, neatly bound in cloth, price 7s. $6 \mathrm{~d}$.

"At a time when the popular literature of the day consisted of Tales of Chivalry and Romance, and all their gorgeous and captivating appurtenances, appeared the deep-thoughted, solemn, and uncompromising Poem of Pollok - the solitary task of a lonely student contending with straitened circuinstances and ill health. His song was of life, death, and immortality; and all that he could have expected to find for it was an audience fit though few. Instead of this, however, the race of its popularity has far outstripped that of every other competitor."-Christian Herald.

\section{DOMESTIC VERSES.}

BY DELTA.

In One Volume, Fonlscap Octavo, price 5s. bound in cloth,

" These poems breathe the purest pathos of human feeling, blended and elevated by the holiest spirit of resignation and of steadfast faith in the promises of Christianity." - Post.

\section{THE POEMS AND BALLADS OF SCHILLER,}

\author{
TRANSLATED BY
}

SIR EDWARD BULWER LYTTON, BART.

WITH A BRIEF SKETCH OF SCHILLER'S LIFE.

In Two Vols. crown octavo, price One Guinea.

"The translations are executed with consummate ability. The technical difficulties attending a task so great and intricate have been mastered or eluded with a power and patience quite extraordinary; and the public is put in possession of perhaps the best translation of a foreign poet which exists in our language. Indeed we know of none so complete and so faithful."Morning Chronicle.

\section{LEGENDS, LYRICS, AND OTHER POEMS.}

\author{
BY B. SIMMONS.
}

In One Volume, small Octavo, price îs. Od., cloth, 


\section{POEMS BY THE LADY FLORA HASTINGS,}

WITH A PORTRAIT BY K. M'LEAY, R.S.A.

Engraved in Line by Horsburgh.

Beautifully printed in Foolscap Octavo, price 7s. 6d.

A fow Copies remain of the Large Edition, which, with Proof Impression of the Portrait, may be had at $15 \mathrm{~s}$.

\section{PROFESSOR WILSON'S POEMS.}

\section{CONTAINING}

THE ISLE OF PALMS, THE CITY OF THE PLAGUE, AND MISCELLANEOUS POEMS.

In Two Volumes, Post Octavo, price $21,1 \mathrm{~s}$.

\section{THE SCOTS MUSICAL MUSEUM,}

CONSISTING OF UPWARDS OF SIX HUNDRED SONGS, WITH

PROPER BASSES FOR THE PIANOFORTE.

(Originally Published by James Johnson.)

A NEW EDITION,

ACCOMPANIED WITH COPIOUS NOTES AND ILLUSTRATIONS OF THE LYRIC POETRY AND MUSIC OF SCOTLAND, BY THE LATE WILLIAM STENHOUSE, AND OTHERS.

In Six Volumes Octavo, price $12,12 \mathrm{~s} .6 \mathrm{~d}$, bound in cloth, with fac-simile of a curious Letter from Robert Burns to the original publisher.

\section{THE LIFE OF ROBERT POLLOK,}

Author of the "Course of Time." BY IIS BROTIIER, DAVID POLLOK, A.M.

With Selections from his Manuscripts.

In One Volume, Post Octavo, with a Portrait, price 10s. 6d. 


\title{
THE JOURNAL OF A CLERGYMAN,
}

\section{DURING A VISIT TO THE PENINSULA IN THE SUMMER AND AUTUMN OF 1841.}

By the Rev. WILI.IAM ROBERTSON, Minister of New Greyfriars, Edinburgh.

In 8 vo, price 10s. 6d.

" He is a lively, graphic, and fearless sketcher, who has caught as much of the gipsy spirit of Borrow as may be seemly in a Scottish Presbyterian divine. For this we like him not a whit the less. It is, indeed, an agreeable surprise to meet with a northern clergyman, who, without levity or any other unbecoming compromise, establishes the most amicable relations between the pulpit and the scenes and incidents of ordinary life."-Tait's Magazine.

\section{LECTURES ON 'THE HISTORY OF LITERA'TURE.}

\section{ANCIENT AND MODERN,}

From the German of FREDERICK SCIILGEL.

A Now Eäition. Foolscap 8vo, price 7 s.

"Form the most luminous, comprehensive, and philosophical survey of the history of literature which our own age has produced."-Britannia.

"A wonderful performance,-better than any thing we as yet have on the subject in our own language."-Quarterly Review.

" Though concise, Schlegel's work is so comprehensive in its range, that it is alone almost sufficient to make the reader a literary person." Literary Gazette.

\section{A LEB STUKELY.}

\section{ORIGINALLY PUBIISHED IN BLACKWOOD'S MAGAZINE.}

\author{
In 3 vols. post 8vo. Price 28s, 6d.
}

"It bears the impress of a fresh and vigorous pen, unworn in the daily toil of seribbling for a taskmaster. It is the produce of a cultivated mind, a feeling heart, an experienced judgment, and a strong intellect. Its author displays a deep acquaintance with human vicissitudes, and an honest desire to guard the unwary, by exposing the deceptions of the actual world. We seldoun have the good fortune to review a work of fiction in which so much that is elegant, pathetic, admonitory, and instructive is to be found united."-Morning Post. 


\section{PEN OWEN.}

Complete in one volume, with Frontispiece. Price 6s.

\section{VALERIUS. A ROMAN STORY.}

Complete in one vol., with Frontispiece. Price 6s.

\section{ADAM BLAIR, AND MATTHEW WALD.}

By the same Author.

Complete in one vol., with Frontispiece. Price 6s.

\section{REGINALD DALTON.}

By the same Author.

Complete in one vol., with Frontispiece. Price 6s.

\section{CYRIL THORNTON.}

By CAPTAIN HAMILTON.

Complete in one volume, with Frontispiece. Price 6s.

\section{TOM CRINGLE'S LOG.}

By MICHAEL SCOTT.

Complete in one volume, with beautifully engraved Frontispiece. Price 68.

\section{THE CRUISE OF TIIE MIDGE.}

By the same Author. Complete in one volume. Price 6s. 


\section{INSECT LIFE.}





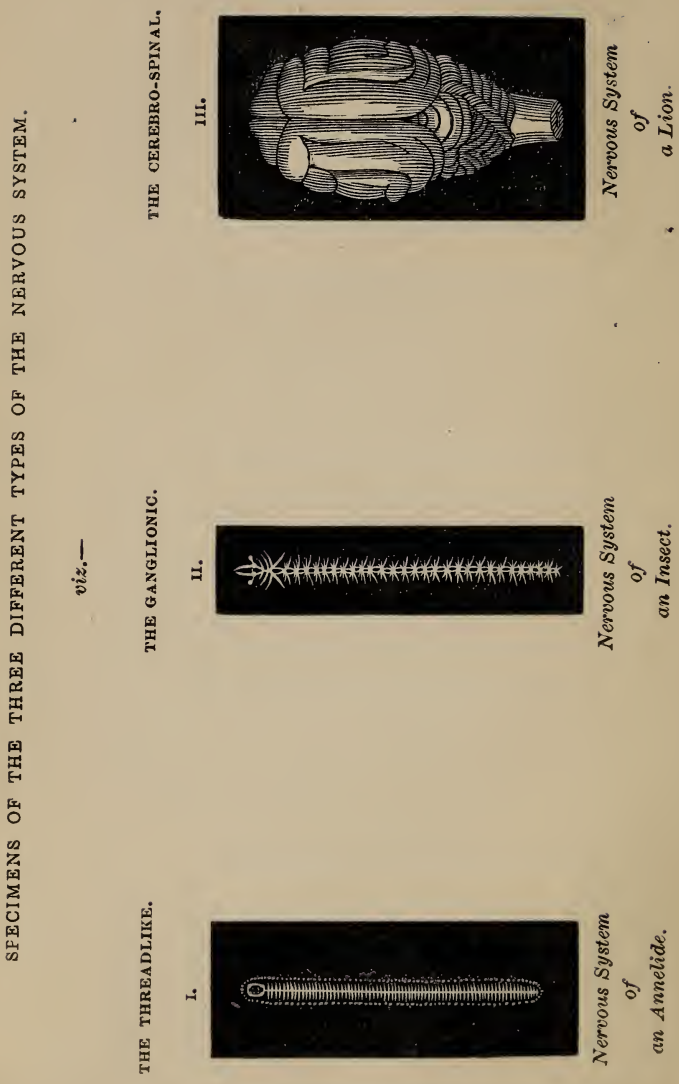




\section{N S E C T L I F E.}

BY

\section{DAVID BADHAM, M.D.}

LATE RADCLIFFE TRAVELLING FELLOW OF THE UNIVERSITY OF OXFORD; FELLOW OF THE ROYAL COLLEGE OF FHYSICIANS OF LONDON ; AND MEMBER OF THE ENTOMOLOGICAL SOCIETY OF FRANCE.

WILLIAM BLACKWOOD $\triangle$ ND SONS, EDINBURGH $\triangle$ ND LONDON. MDCCCXLV. 
"Cerebrum omnia habent animalia quæ sanguinem: hoc est viscerum excelsissimum, proximumque cœlo capitis, sine carne, sine cruore, sine sordibus. Hanc habent sensus arcem; huc venarum omnis a corde vis tendit, hic desinit: hic culmen altissimum, hic mentis est regimen."-Pliny, Nat. Hist. Lib. xi. cxlvi.

"There are not many certain truths in this world. It is, therefore, in the anatomy of the mind as in that of the body: more good will accrue to mankind by attending to the large, open, and perceptible parts, than by studying too much such finer nerves and vessels as will for ever escape our observation. The disputes are all upon these last."-PoPE's Preface to the Essay on Man. 
THOMAS BARRETT LENNARD, ESQ.

THE FOLLOWING PAGES ARE AFFECTIONATELY

DEDICATED B Y HIS SINCERE TRIEND,

THE AUTHOR. 



\section{IN S E C T LIFE.}

"Liceat irrideat is qui velit; plus apud me tamen vero ratio valebit quam vulgi opinio."-Cicero.

THE general characteristics which distinguish the animal from the plant, manifold as they frequently are, and not difficult to be discerned, do not, nevertheless, enable us to lay down the exact and formal limit between these two great departments of nature. Distinctions, which might be considered as belonging to the animal alone, if he is contemplated only in his higher grades, become so much fainter in those classes which lie in the neighbourhood of the vegetable kingdom, that it would be difficult to point out the object in which they have wholly ceased to exist. For in every class, excepting only in the highest, in which all the peculiarities of the animal are combined, we find either some characteristic to 
be wanting, or to be altered in degree, or to be combined with attributes belonging to plants. Thus, if, with Decandolle and other good authorities, we adopt the simplest of all distinctive marks-difference of structure ; and if we proceed to admit or exclude doubtful claimants, according as they possess or are destitute of nerve or muscle, we must reckon as among plants, corals, sponges, infusoria, and other tribes, which, beyond this negative resemblance, have nothing in common with them. The view of the subject adopted by Plato, which supposes the fact of movement conclusive, and which reckons all organized bodies that do not possess the faculty of motion, (except in so far as growth is motion,) and by the law of nature abide in one spot, as plants ; and all such as are capable of shifting their abode, and accomplishing the change by a motive power acting from within, as animals - fails before the just remark of Aristotle, that many animals remain motionless through life; and further observation has enabled the modern physiologist to add, that "many plants have the faculty of topical motion -i.e. movement through successive spaces." It has also been asserted that animals subsist upon organized and unorganized food indifferently, plants exclusively upon the latter; and that this difference in their nourishment, as well as the difference 
in the mode of their deriving it, is sufficient to distinguish them from each other; but this cannot be conceded, inasmuch as lichens, sea-weeds, and funguses, all of which are undeniably vegetables, derive their nourishment, in most cases, from decaying, and sometimes even from living, organized matter. Nor does the distinction made between the outward and inward apparatus for the assimilation of food-in other words, between the stomach of the one, and the absorbing radicles of the otherhold good in all cases: for all animals have not a stomach, though most of them have; while some plants, such, for instance, as the "Dyonœa muscipula," have an organ which very much resembles a stomach. Neither can propagation by slips be said to be peculiar to plants, since certain leeches and polypes may be multiplied by chopping a single one into morsels. Nor can the comparative longevity of plants avail as a ground of distinction, for it is well known that many plants live for a very short time; in support of which assertion, the ephemeral growths of the Tropics may be especially mentioned. It was for some time supposed that azote was an element peculiar to animal matter; but whatever conclusions might have been drawn from this fact, have been nullified by the discovery, that not only elementary azote, but such substances as osmazone, mucus, and 
gelatine, (of which azote is largely an ingredient,) enter into the constitution of certain plants. The proposition which was advanced by Aristotle as a philosophical doctrine, that sensibility is the common difference, or distinctive attribute, of animals, rests on no better grounds than a certain apparent fitness, that a great division in the nature of organic being should be marked by a corresponding division in the living powers, or different intensities of life. Moroever, as we have no reason to believe that plants feel, and as the domestic animals, with whom we are in more immediate intercourse, undeniably do, it is not surprising that in the infancy of knowledge in that important branch of science, Natural History, men should have imposed upon nature (as though it were one of her own rules) this fiction of the understanding, that sensibility must necessarily belong to every order and species of animal life; and even supposing this to be true, we must, unless we would reason in a circle, find the one boundary before we can declare that the other coincides with it; and have ascertained by characteristic marks to which of the kingdoms any given object belongs, before we are in a condition to affirm that it does or does not feel. Besides, there is an assumption lurking under this notion which it is worth while to examine. The possibility of fixing any limit between 
the two kingdoms presupposes that the highest order of plants is lower than the lowest specimen of animal life; whereas, to the careful observer, the scheme of nature does not present a graduated scale, on which every class is necessarily higher or lower than the next; there being many living productions which, while on several grounds they bear a stronger analogy to the animal world, are yet, in other respects, (such as complexity of organization or variety of function,) lower than ferns or lichens, or even than some of the phanerogamic classes. When indeed we arrive at less questionable examples, wherein may be traced the substance of one order and the machinery of another, the voluntary motion of this tribe and the irritable tissues of that, coexistent in all their completeness, every thing which is considered necessary to the constitution of an animal is so unequivocally present, that any one would be laughed at who should refuse to bestow that title on their possessor, (an insect, for instance ;) and yet by the familiar use of this word, animal, we are led to form conclusions unsupported by experience, and, starting with the belief that it implies "a being that feels," we argue from the name to the fact, and from the fact back again to the name.

I hope what I have already said has in some degree prepared the reader to receive the first obser- 
vation which the subject requires me to make; viz. that insects do not feel. Of course this is still only an assertion, though $I$ hope not so startling as it might have been, but for the considerations by which it has been preceded. A popular treatise is bound to meet popular objections as early as possible, in order that whatever the author has to advance on his own account may be received without prejudice; and for this reason it is better, at once, to notice the first objection which will probably be made to this hypothesis. How, it will be asked, can that which is endowed with voluntary motion be destitute of sensation? For it is only the undoubting persuasion that sensibility and motion are two phases of one and the selfsame life that causes our compassion to be, as it were, instinctively engaged on behalf of the writhing worm, and that we maintain not only that he feels, but that he moves because he feels. The discovery of a distinguished philosopher of our days, which bears immediately upon the point, is sufficient, as it appears to me, to correct this error-for undoubtedly it is an error to consider motion and feeling as inseparable. Sir Charles Bell, moved no doubt by that "Prudens questio" which has been so justly declared to be the half of philosophy, applied himself to the examination of the nerves which had hitherto been supposed to be the vehicles of 
either process indifferently, and obtained a clear demonstration, that, as Galen and Aretæus had sus: pected, although the filaments which minister to motion and sensation are very intimately united, they present two distinct substances fulfilling two distinct offices. The subservient apparatus being proved different, what reason is there to contend that the connexion between the two functions is so intimate, that the presence of the one must imply that of the other? I shall have to speak more at length upon this matter hereafter. Let it suffice for the present to remark, in the way of familiar illustration, that in a certain kind of palsy the limb is so alive to irritants, as to contract, and even to be violently convulsed, when they are applied; while the palsied man is as unconscious of pain, as is the sensitive plant when a similar experiment is performed upon it. In both these cases the organ, though unsentient, is alive to impressions through its structures. This capacity for being acted upon by the outward world is so clearly recognised by Bichat and others, as distinct from sensibility, and inferior to it, that it has received the separate name of irritability.*

* To an attentive and informed reader, it need scarcely be suggested, that we cannot be conscious of unconsciousness; and that sensation itself is inconceivable as existing apart from intelligence and spontaneous movement-properties which we 
The true and adequate expression of irritability is motion, where a partial affection of the nervous material issues in a partial act; and a distinguished German philosopher, ${ }^{*}$ persuaded that sensation is a predicament of the whole creature, and should therefore have assigned to it some more adequate act than motion, suggested voice as its true exponent. How far this is in accordance with facts, we shall be better able to judge if we first direct our attention to the anatomical conditions of sentient life.

It is instructive to observe the principle on which the gifts of nature seem to be distributed. It would appear to be only when any given power has attained the highest intensity of which it is capable, that a further and higher prerogative is superadded to it. Thus, reason is first displayed in the creature who is already in possession of the highest intelligence, while intelligence attests the complete development of the sensitive faculty; and so, the power to feel, as I intend to show, appertains only to those

attribute to ereatures too low in the scale of life to possess memory, which is the ground of desire. The moment we endeavour to comprehend it as a positive state, insensibility acquires the properties of a self-adapting intelligence, and, finally, of a reasonable will. The state of self-consciousness requires not only a "subjectum conscitivum," but also an "objectum conscibile."

"Hegel. 
creatures in whom the life of growth has reached its consummation. It is admitted on all hands that higher degrees of intelligence are associated with higher degrees of anatomical structure, especially of the neryous system; and it is equally certain that the sensibility of creatures is in proportion to their intelligence:* hence we should expect sensation to be more or less perfect according as the nervous system is more or less developed; and its amount to be immediately connected with all those physical conditions upon which intelligence has also been ascertained to depend-viz. the temperature and colour of the blood, the absence or presence of a spine, and the form and substance of the brain. Accordingly, it ought to follow that the sensibility of creatures of cold blood, such as fish, amphibiæ, and reptiles, where few or no traces of intelligence can be discerned, should be proportionably low; and in point of fact, the signs of it are very faint, and few. Surely, therefore, when we descend lower still, and come to creatures of the same kind as Anacreon's cicada-creatures altogether without blood-and this

* Remark the indifference with which a pigeon continues to pick up grain in the neighbourhood of the trap, from which he has just risen covered with wounds; and it is a well-known fact, that a rabbit will continue to crunch cabbage with his bowels protruding. 
deficiency is common to all the insect tribes-it is reasonable to expect that the sensibility, of which we had observed the progressive decline, in passing from the higher to the lower qualities of the circulating fluid, should here be wholly obliterated.

The division of animals into vertebrata and invertebrata, goes at once to their most striking peculiarities, and, by a single anatomical feature, ascertains their place in the scale of life; for the vertebræ, as is well known, derive their chief importance, not from their constituting a flexible spine, but from their affording protection to the immediate prolongation of the brain, or spinal cord, which, passing out of the skull, is received into their canal. In this cerebrospinal axis, all that qualifies the animal to feel is centralized, and from the same originating cord all that enables it to move proceeds to its destination. As it had been long since known that injury to the spinal cord caused loss of motion to the parts below, so it had been also conjectured, from the consideration of other phenomena, afforded by injury, experiment, or disease, that this cord was in all probability a compound body, giving origin to two sets of nerves, the one for motion, the other for sensation. Now, instructed by Bell, we have the assurance that the "anterior column" of the spinal cord supplies the nerves of motion; while the posterior administers 
only to the sentient life: and where the nerve has a twofold office to perform, in communicating feeling and motion to a part, it has a twofold origineach column supplying it with a root. The nerves of sensation, and these only, exhibit at their spinal termination a remarkable enlargement, to which the name of ganglion has been given. The heart, the lungs, and the stomach, receive their supply of nervous power from another source, not within, or proceeding from the spine, but from a tissue of nerves, sometimes called, from their threefold distribution, "trisplanchnic;" sometimes, from the consequence of that distribution in establishing pathological relations, sympathetic. All vertebrated animals are constructed more or less conformably to the above type: but this is not the whole; for all of them, at the same time, possess a nervous centre or brain. However greatly the brain may differ in superficial appearance, and in structural arrangement, it never differs as to its situation in the body. It is also always divided longitudinally into two principal parts-an anterior, or cerebrum, connected with the nerves of the organs of sense; and a posterior, or cerebellum, a sort of appendage to the first-and laterally, into two hemispherical masses, the external surface of which is always of a darker colour than that of the internal mass. The development of those 
cerebral hemispheres is at its maximum in man : in the Simiæ they are considerably flatter ; and in beings of less intelligence, the whole organ becomes less and less convex, till at last the furrowed appearance, and the deep cleft between them, cease to be perceptible. Or, if the lower order of Mammalia be taken as examples, it will be found that even when the surface of the brain has already passed through some steps of progressive development-as in the Montremata and Rodentia-its surface can scarcely yet take the name of convoluted; that in the Cetacea and Ruminantia, the furrows are still shallow; and that they do not, until we come to the Carnivora, assume a distinct character. If the external appear-, ance of the brain differs much, the varieties of its internal structure, according to the varieties of the animal, are no less remarkable. In proportion as the creature is more perfect, the nerves which minister to the special senses, become, in relation to the brain, of smaller size-a fibrous arrangement of the cerebral mass becomes conspicuous, and the crossing of the fibres more intricate ; the parallel set, which connect the external convolutions with the internal core of the brain, are in the higher orders of being intermixed with a transverse fibrous tissue-a crossgrain, as it were, of the solid; an arrangement which necessarily compacts the substance more intimately 
together. It is in the disposition of this intercerebral fibre, that the brain of man differs most from that of all other creatures; for some animals have, in proportion to their bulk, as great, or a greater quantity of brain than man. While it may be stated, generally, that there is a connexion between the bulk of brain and the extent of mental capacitythe weight of the human brain, as compared to that of the whole body, being as 1 to 35 ; in the dog, as 1 to 120 ; in the horse, as 1 to 450 ; in the "dull ox," as 1 to 750 ; and in fish, which show very. doubtful signs of any intelligence at all, only as 1 to $2000 ;$; - still the rule will not be found applicable in all cases, for the brain of a mouse, (a creature not conspicuous for his intelligence,) weighs about onefortieth of the whole animal, and the brains of many small birds, such as the chaffinch, robin, \&c., weigh nearly as much as that of the mouse. But the intelligence of an animal is not to be calculated merely by the relative size of its brain to its body, since it is also found to depend, very materially, on the proportion which the external, or gray, matter bears to

* All these weights are mere approximations to the truth, since the weight of the brain in each animal is fixed, while that of his body varies.-Too little attention to this circumstance has led one author to estimate the weight of a cat's brain, as compared to his body, as 1 to 85 ;-another, only as 1 to 156 . 
the inner, or medullary part, (owing to which, the first has been, by some writers, supposed to minister exclusively to the intelligence of the creature, the second to its animal functions:) at any rate, the convolutions of the brain in man seem intended principally to increase the extent of this gray matter, which dips down along with them through their whole extent; while in the highest quadrupeds, the convolutions being less deep, the gray matter is less developed, and in fish there is scarcely a trace of it remaining.

After this brief statement, in which there appears an undeniable connexion of the higher class of functions with the more complicated structure of the nervous system, let us take a view of the analogon of this system, as it is found in insects. A medullary cord runs through the whole body of the animal, giving branches to the different organs in its way. This cord is either single, or consists of two threads, which may either touch, or lie at some distance from each other; each of these parallel cords being composed of two distinct columns of fibres, which are placed one over the other, and closely united: one has been regarded as the substitute of the sensorial, the other of the motor column of the spinal cord, in vertebrated animals. Placed at intervals upon this cord, something like beads, or lying between its two 
elementary threads, are seen roundish knobs, which have obtained the name of ganglia : they are various in size, are uncertain in number, and are placed at unequal distances, in different tribes of insects; but in no case do they, as far as visible structure is concerned, present the least similarity to the brain. It is obvious, then, that insects are totally unlike vertebrate animals in relation to this part of their nerrous system.* In spite, however, of this dissimilarity, and of the conviction which most naturalists entertain, that this order of creatures is devoid of brain, some few, unable to reconcile the acts of insects with the absence of so material an organ, have set up an hypothesis, that every ganglion is in fact a substitute for a brain; while another party, aware of the inconvenience of such an admission, but still agreeing in the necessity of such an organ, would restrict the name and the office to the first or second ganglion in the series; nay, there is a third view, or guess, on the subject, which is, that it is the united force and consent of the ganglia taken

"No notice is here taken of the nerves called "vagus," or sympathetic, because as both are exclusively destined to the maintenance of visceral life, they have nothing to do with sensation. The reader desirous of a full and accurate account of the distribution and connexion of these nerves, will find it in Mr Newport's "Insecta," published in the "Cyclopedia of Anatomy and Physiology."-Part XVIII. 
together which executes the function of the brain. Now, in order to prove that the first ganglion is by itself equivalent to a brain, it should be shown that it possesses some title to this preference, either in its substance or else in its size: but none such exists; for all the ganglia are formed of the same material. Sometimes the head ganglion is smaller than the others, but in most instances (as in the centipede, which passes with entomologists as a model-insect) it is not more than equal to them. The occasional origin of the nerves of the so-called eyes, and of those also of the antennæ, from this ganglion exclusively, has been urged as a difference sufficiently important to justify the important distinction attempted between the first ganglion and the rest; and the fact would undoubtedly be worthy of consideration were it universal, or were the nature of these two organs clearly demonstrated; but neither does the first ganglion always send off supplies to the organs in question, for they do not always exist-nor can we determine with certainty, what precise purpose the organs themselves, when present, are intended to answer, inasmuch as the failure of analogy in essential particulars makes it difficult to look upon them as organs of sense. As I shall have abundant occasion to notice this part of the subject when I come to speak of the senses in 
detail, I shall content myself with remarking, that, although the word " eye" immediately suggests the idea of sight, it cannot be deemed impossible that, in some orders of creatures, the eye should serve merely for the intromission of the stimulus of light to fulfil other purposes in their economy. It is proper also to recollect, that this organ exists in creatures which have no nervous system at all, and which must, therefore, have eyes without sight. Moreover, it is exceedingly difficult to say what purpose is answered by antennæ; for before the advocate for the sensibility of insects calls them "feelers," and would thus make them appear to be organs of touch, he should remember that the spider, whose fingering of the loom exhibits, according to his views, the most extreme delicacy of touch, has no antennæ. Insects which have neither eyes nor antennæ in the first stages of their existence, sometimes possess them in a later stage: but this does not prove them to be organs of sense; for to say they are organs of sense, is to say they proceed from a brain. And if the same substance were to be considered brain, or not, according as antennæ did, or did not, spring from it, then that which in the caterpillar (who has no antennæ) would be merely a ganglion, would in the butterfly have become a brain; and so the same animal must be reputed unsentient in one stage of 
its life, and sentient in another-that is, would differ from itself considerably more than any two individuals in even cognate genera are known to differ. But, perhaps, it will be here suggested, that in the life of the human fotus, a time must be supposed (before the brain and nervous attachments are formed) wherein, owing to their not being sufficiently developed, sensibility, which comes afterwards, is still wanting. Small indeed, however, is the analogy between embryogenic life and that of a caterpillar. The fotal brain may be said to assume, in its successive stages of progress, the various forms which distinguish that organ in the fish, the reptile, and the mammalia; it goes on from imperfection to perfection: whereas the insect does not present one more organ, nor execute one more function, on the day when he was about to spin his cocoon, than on that when he first came forth from his shell. In no sense can the caterpillar be called the foetus of the butterfly: whatever, therefore, the latter possesses of which the former is devoid, must be considered as a contingent adaptation to a new mode of life, and not the organ of a higher life superadded to the same being. It would seem, then, from some of the foregoing considerations, that there exists no sufficient reason, arising out of difference of structure, either for considering the first ganglion better than 
another, or for believing that one of them singly, or all of them together, can be the representatives of a brain, or in any way execute functions analogous to those which it performs.* The reader the least versed in anatomical researches and physiological conclusions, need scarcely be informed, that the connexion between the brain and the bodily members is such, that, at whatever point the communication between them is cut off, insensibility and immobility of the parts below the injury immediately ensue. But as insects are able to move, to walk, or to fly, without their heads, (and at first almost as actively as with them,) their upper ganglion cannot be a brain. Mr Kirby mentions having seen a headless wasp walk, and a cantharis in the same condition perform one of the most important functions of its nature. Lyonnet saw another wasp alive three days after the removal of his head. I have myself seen ants,

* Mr Newport considers the supra-œsophagœal ganglion as a brain. The sub-œsophagœal, or the next to it, as the medulla oblongata, and the nervous collar which surrounds the osophagus, and connects the two, as the crura cerebri. He has not, however, substantiated the analogy here pointed out. The osophagoal collar is no more entitled to be designated as the crura cerebri to the first ganglion, than any subsequent deflection of the threads between any other two ganglia is entitled to be considered as the crura of the first of those two; and if the second ganglion was really the representative of the medulla oblongata, should we not expect to find the nerves in its immediate neighbourhood differently distributed? 
and many kinds of Melasomes, walking without their heads. Caterpillars do the same, and, when touched, show all their usual signs of impatience. Certain observations, however, having been made on worms, which appeared to countenance an opposite conclusion as to the value of the head, I thought it incumbent on me to repeat the experiments; and what fell under my observation did not, by any means, agree with that of which I had read. Instead of the amputated head and shoulders moving away, and leaving the tail powerless, as in the experiment of Sir Charles Bell, both halves began to move off at nearly an equal rate; and although the headless portion was perhaps, of the two, the least active, and remained motionless for a short time, yet both parts soon acted much in the same way as the entire creature would have done. When the worm had been cut into a great number of pieces, there was no perceptible difference in the progressive motion of any of its parts. All stopped at last; but the death, or final cessation of motion, in the different pieces, seemed to me to depend on their relative size, the largest retaining its vitality longest. The application of chemical irritants, or poisons, produced just the same results: the part to which the application was made was thrown into violent cortortions, and shortly ceased to move; but it made no difference, as to the time required to extinguish the 
diffused vitality of the worm, whether the application was made to the head, or to any other piece. In the Scolopendron, where the ganglia are equal in size, we should expect the vital principle would be equally divided; whereas the greater amount of vitality appears in the lower half; for Shaw repeats, what Unger had already asserted, that, when the Scolopendron electrica is cut in two, the halves rot only live, and exhibit vigorous movements for even a fortnight afterwards, but, what is more remarkable, that the tail-part always survives the head for some time. The body of a fly survives for some time the removal of the head, but the head itself dies directly; the head, in this case, being more dependent for life on the body, than the body on the head. So that, as Pliny says, "Quæcunque est ratio vitalis, ita non certis inest membris sed in toto eorpore, minimeque tamen in capite." Long before I was aware of this passage in Pliny, or of a subsequent one, in which the Roman naturalist states, on the authority of Aristotle, that "the portions of a divided insect move independently," I had ascertained, as above stated, that life would remain in the disconnected pieces of the worm, or scolopendron, sometimes for hours, sometimes for days; and also, that the period of final extinction differed in different insects. In some instances there may have been a somewhat 
greater tenacity of life in the portion to which the head was attached, but the difference was never considerable; and where the first ganglion is the largest in size, affording, so to speak, a larger depository of nervous power, the difference would be sufficiently accounted for by that simple consideration. In short, when parts can no longer act in concert, they soon cease to act in detail; and the length of time, often not inconsiderable, during which they continue to manifest signs of life, leads to the inevitable conclusion of their not deriving supplies from the head.

The case of the snail, whose nervous system is of the same type with that of insects, affords yet more direct evidence that the first ganglion is neither a brain, nor in any one respect superior to the other ganglia. Spallanzani not only found that a snail's horns were soon restored again after removal, but even in those cases where the whole head had been removed, the snail often recovered, and at the end of a few months appeared with a new one, equal in all respects to the former. "The snails so treated, the moment the operation was over, retired into their shells, and there concealed themselves for weeks, or even months, covering the aperture with a parchmentlike secretion. When forced out at the end of thirty or forty days for examination, some appeared without any marks of renewal ; but in others, especially 
in warm weather, there was seen, towards the middle of the body, a soft fleshy globule of a whitish ashcolour; in eight or ten days the globule became larger, and rudiments of lips, horns, mouth, and tongue, were discernible: the nascent parts continued to become more and more developed, until, at the end of two or three months, the injury was so completely repaired, that it was only by the lighter colour of the new head that it could be distinguished from the old one."

If the first ganglion cannot be a brain, neither can the second ; indeed, the especial purpose of the latter seems indicated by its position, and by the four pairs of nerves which proceed from it-those which go to the labium, to the palpiform maxillæ, to the muscles of the mouth, and to the salivary organs. Aristotle has left on record a curious conjecture, that the source of life in insects must lie in some midway region of the body, because the head, if removed from the corselet, or thorax, immediately perishes ; whereas it survives for a considerable time if the præcordial region remain attached to it. For such a fact I am inclined to find a simpler reason, in the consideration that any two parts of an insect being larger than the third, must be in possession of a greater amount of vitality.

By other enquirers it is suggested, that each 
ganglion may be a sort of independent brain, and if not, like our own, a citadel of intelligence and the headquarters for mental acts, at least a depositum, or centrum commune, for so much sensation. Kirby thinks that they are so; because "if the head be cut from an insect, the remainder of the body will continue to give proofs of life and sensation longer than the head" - which is as much as to say, that from one sentient individual two are propagated by mere mechanical separation-i. e. that self can be cut in two, and become two selves. Thus the authors of insect-transformations speak of each ganglion as "forming a centre of feeling to the parts to which its nerves run," and imply, that it is on account of this subdivision of the sources of feeling, that insects, after grievous injury or mutilation, will live, and, so far as can be perceived, feel " comparatively little general pain from the loss of their limbs, or even of their heads."

-(Insect Transformations, p. 400.) Comparatively little general pain! Dolus latet in generalibus! But, not to object to the vagueness of expression in this sentence, how can there be more than one seat of sensation* any more than one seat of intelligence,

* Such a notion sounds strange even as a conceit:-witness the following passage from Cowley.-

" The mighty serpent Love,

Cut by this chance in pieces small, In all still lived; each little broken part Felt the full pang of all." 
without a contradiction in terms? For what is sensation but a self-finding, as it has been excellently defined; and in a merely sentient creature does it not constitute the individual? And would not a plurality of seats of sensation disintegrate the creature, and make many individuals within one organization? But even in an unsentient animal, though there is no local centre, ${ }^{*}$ there is a connexion, and that a very close one, between the ganglia; much too close to allow us to conceive of them as so many independent seats of life, otherwise the several pieces of a centipede or caterpillar, through the ganglionic independent life of each, would become just so many centipedes or caterpillars-all separable upon occasion, yet all capable of consolidation into one compact existence; which that they are not, is proved by the ultimate death of such pieces separated from the body. Even in those rare cases where the parts into which certain leeches and worms have been cut multiply like the gemmules of plants, and become each a new individual similar to the original whole, we are not to conceive that such parts, during the integrity of the worm or leech, were endowed with

* Irritability, or the ganglionic life, not being arrived at this positive union with itself, being only, as $\mathrm{Mr}$ Coleridge has expressed it, " a self-seeking power," is not attached to a single centre. 
so many lives-else how could the animal manage his whole body? - to do which a most exact harmony and mutual understanding between the ganglia is indispensable.* Furthermore, as stated above, a theory has been advanced, that not any ganglion in particular, but the sum of all the ganglia together, may possibly fulfil the office of the brain; nor is there any thing intrinsically absurd in such a speculation ; for, in the first place, the brain is a compound organ; and, in the next, there can be no a priori reason why any particular configuration should be required. It is therefore quite conceivable, that ganglia ever so numerous, or ever so widely dispersed, if connected by a nervous cord, may form together a homogeneous whole, the parts severally representing

* When a worm or a leech is set in motion by an agency from within, are we to suppose a single agent, or a chorus of agents? If the former, then it follows that there is a principle which individualizes the life of the creature, and which out of "life" makes a life; if the latter, we must go a step further back, and suppose the ground of this agreement betwcen the conspiring motive-forces, and that will be the principle of motion as the mover of the movers, the prime agent in reference to which the vital forces residing in the several ganglia are but secondary and instrumental. Thus, in both cases, unity must be supposed as the condition of a living act. In animals endowed with intelligence, we not unfrequently, though still very incorrectly, call this unity a will; but the source of motion in a leech or a worm, is assu. redly not intelligent. These animals are not one essentially, (or they could never become more than one,) but accidentally, and therefore neither require nor possess a single seat or brain. 
the detached plates of a Galvanic pile, which, under the requisite conditions, might act in unity. In opposition, however, to this view, it has been already shown that each ganglion, if severed from the rest, is not only capable of supplying life for a time to the segment in which it resides; but, as has been mentioned, of producing even a new head, or some other organ, with which the living fragment may be unprovided. Each ganglion is, in fact, far too independent of the others, to enable us, even for a moment, to admit the probability of their combined force uniting to become a brain. Enough has now been said to prove, that an appeal to facts will not bear out either of the three views above stated, which regard as the representative of a brain either the head ganglion, or each ganglion, or the sum of the collected ganglia, in insects.

The nervous system of these creatures in the distribution of its vagus nerve, and of what has been properly called the sympathetic, evidently bears a close resemblance to the asymetric system in vertebrate animals, the exclusive office of which is to preside over visceral life. There are also some strong points of analogy between their ganglionic cord and the spinal cord of the vertebrata. It is well known that if a small segment be cut off from the spinal column, together with the parts which are 
supplied by it with nervous influence, motions may be excited in them for some time after, by irritating the nervous matter within the spinal cord; and it is as certain that, after the removal of a segment of the nervous cord of insects, to which any member remains attached, motions will at first ensue, which may be renewed afterwards by mechanically irritating the part. If the head only be removed from the bodies of some vertebrata, as from a snake, a tortoise, an eel, or a salamander, their progression is not suspended; showing that the associated movements on which progression depends, even in creatures that have a brain, are not derived immediately from it, but rather from the spinal column. It is also found, as has been already stated, that if the head be removed from an insect, he will, notwithstanding his loss, continue to fly, run, swim, or spring into the air, (according to the nature of his movements,) just in the same way, though not for so long a time, as if he had been in possession of his first ganglion. Thus, then, the nervous system in insects appears to be a compound organ, here, executing the function of the great sympathetic in supplying the viscera,there, resembling the spinal marrow, in so far as that organ appears to be engaged in harmonizing and associating the complex movements among parts on which progression ultimately depends. Beyond the 
two offices here assigned, which are proved to exist, and to be performed by the nervous material of insects, no other is apparent, and no other need be supposed, since " associated movements," or, in other words, progressive motions, of all kinds, (as they continue after the removal of the brain,) cannot require either sensation to excite, nor the guidance of an intelligent principle to maintain them.

As it is obvious that any close similarity of structure existing between insects and the higher order of being, would make it probable that a resemblance should obtain in other endowments also, and consequently in that special endowment which is a main object of our enquiry-sensibility ; so, on the contrary, every point of structural resemblance that insects can be shown to have to things in which the attribute of sensibility is out of the question, is so much argument against their possessing it.

The physiology of insects, in several points, resembles that of plants rather than that of animals. In insects, as in plants, not only the perpetuation, but the superfoetation of species, appears to be intended; and as soon as that end is accomplished, the plant perishes, and the insect dies. Plants, if they become double, and therefore fail to produce seed, live much longer than they would do otherwise. Pinks, if they do not flower, live for several years; 
but if they flower during the first year, they soon after perish. The corypha, or umbrella pine-tree, remains barren thirty-five years, starts up seventy feet in four months, puts forth fruit and blossoms in the same year; and dies, root and stem, soon after. So female butterflies, shut up in a room, may be kept alive for six months: but if care be not taken to prevent their breeding, they die as soon as that end is accomplished. Efflorescence, and some other vegetable phenomena, are attended with an extrication of heat; but, unlike that of animals, it is only for the occasion. Placed in the spadix, or flower-case of an arum, (which, acting as a non-conductor, retains the heat as it is extricated by the plant,) the mercury of the thermometer has been seen to shoot up to $112^{\circ}$ Ft., the air without being $66^{\circ} \mathrm{Ft}$. The same occasioned development of heat is noticed in certain insects. Thus, in an irritated hive of bees, a temperature reaching, as I have been informed by some naturalists, to $100^{\circ} \mathrm{Ft}$. has taken place, making the "fervet opus" of the poet to be literally true. Hornets, wasps, and bees have been found to raise, by several degrees, the temperature of a phial in which they were confined; but, on whatever occasion heat is excited in plants or insects, it is brief, and ceases with the occasion. This is not the place to investigate the cause of this phenomenon; but in 
regard to insects, I have been led to suppose, from observing it to occur only in such as have wings, and are in full activity, that the wings themselves produce it by bringing an increased quantity of oxygen into contact with the respiratory apparatus.* The analogy here suggested between plants and insects, is the rather to be urged, because it applies immediately to the question of the insect's sensibility in the following manner: A direct connexion has been established between the temperature of animals in general, and the amount of red globules in their blood. Where these most abound, as in birds and mammalia, the animal heat is considerable. Where this cruorine fails, or forms but a small part of the circulating mass, the temperature is comparatively low. Indeed, so regularly does the one decrease in proportion to the deficiency of the other, that, even amongst the cold-blooded tribes, those which are colder than the rest differ from them also in the quality of their blood. Fish are colder than reptiles, and of fish those have the least heat which have the whitest flesh. River-fish, whose colourless solids are supplied by a blood more than usually deficient in cruorine, are also colder, by several degrees, than sea-fish; or, at least, than such sea-fish

* If this supposition is correct, then Dr Carpenter is wrong in thinking that insects are cooled by the action of their wings. 
as have darker solids. Some beautiful experiments by Edwards, to which I refer the reader, have put the correctness of these statements beyond a doubt. Now there is as marked a connexion between the amount of sensibility and of animal heat, as there is between animal heat and the amount of cruorine in the blood. In the healthy, or physiological condition of the human body, the hands are numbed in a frost, and have their sensibility increased by warmth. In the pathological condition, the increased heat and sensibility of the skin, in some eruptions, may be contrasted with the diminished temperature and the departing sensibility which announce gangrene. An augmentation of the general sensibility of the sentient organs attends the fever-stage of reaction, while the cold, earthy skin of typhus, is connected with impaired sensibility. The least sensitive parts of the body are the least capable of maintaining their natural heat; tendons and ligaments, which derive their temperature from blood not their own, are as deficient in sensibility as they are in selfengendered heat. If animal heat depends thus upon the presence of red globules, and if sensibility varies thus directly with animal heat, the latter will be in proportion to the amount of these red globules; and it is therefore fair to presume that a creature which 
has no red blood, (such as an insect,) should be devoid of sensibility.

There is another important general fact which tends to the same conclusion. In man, and in the warm-blooded classes, the brain is larger, more convoluted, furrowed, and complete in its structure, and fills the cavity of the cranium. In cold-blooded animals, the brain is comparatively small in volume, and simple in character, and do'es not completely occupy the cranium. Fishes, defective in blood, may have large heads, but they have very small brains. Compare the inconsiderable amount of brain in a large cod's head with the proportion allotted to the partridge or the snipe. The rule seems to be, the more red blood, the more cerebral development. The amount of cruorine and that of brain, seem invariably connected. Since insects, therefore, want that elevated and self-supported temperature which is called animal heat; since they are without red blood, or, indeed, any blood properly so called; and since, above all, they are destitute of that organ which we recognise as the physical organ of sensation-brain-all the considerations derivable from comparative anatomy and physiology, concur to justify a denial to them of the attribute of sensibility.

There is yet another point of analogy to be men- 
tioned between plants and insects; viz. the power which some of them possess̀ of generating spontaneous light! - a power of which beings higher in the scale of life are destitute. Certain flowers, particularly those of an orange colour, emit light, sometimes in jets, sometimes in a continuous stream. Linnæus relates that his daughter had observed occasional corruscations about the petals of the Tagetes, the Lilium bulbiferum, and other yellow plants; and though Treviranus expressed a doubt of the accuracy of a statement which others, besides Linnæus, have also made, and endeavoured to explain it away as an illusory effect of the colour itself, as seen by twilight, there can be no doubt that several kinds of funguses, particularly the Rhizomorpha subterranea and acidula, and the Agaricus olearius, emit light of sufficient intensity to see to read by. This light is dependent for its exercise on the vitality of these plants, and it ceases if they are placed in vacuo, or in irrespirable air. The bodies of several insects exhibit a like phenomenon, while creatures still lower in the scale of creation illuminate sea and land by a profusion of light, emanating from themselves; but no similar property has ever been seen, or pretended, in bird, beast, or reptile.

The action of poisons on the economy of insects, shows a "modus operandi" similar to that which 
occurs when they are applied in the vegetable kingdom, and altogether unlike to what is observed when they are placed in contact with higher animals : the chief ground of this difference being, as I conceive, the absence of a "sensorium commune" in plants and insects.

Writers on Toxicology divide poisons, according to their supposed mode of affecting the animal economy, into three classes, viz. the acrid, narcotic acrid, and narcotic; to which Orfila has added a fourth, including septic substances, and the stings of poisonous and rabid animals. For our immediate purpose, a twofold division of these substances will suffice; first, such as kill suddenly, by the shock which they convey to the brain; and secondly, such as carry their noxious influence elsewhere by absorption: thus animals may be poisoned slowly, or at once. Arsenic, phosphorus, elaterium, strychnine, destroy in the first mode; opium, and other narcotics, prussic acid, and alcohol, if taken in sufficiently large quantity, destroy life as suddenly as pressure on the brain, or as a flash of lightning. Decandolle proved, by experiments, that no plant can be killed outright by any poison, however violent its nature; but that the organization, in such cases, perishes little by little. Even arsenic, one of the most rapidly fatal poisons to the vegetable kingdom, does not do 
its work directly. A French bean, placed by Marcet in a solution of the white oxide of this metal, (two grains to the ounce,) did not begin to fade till thirtysix hours had elapsed. In another solution six times as strong, a rosebud did not change colour during the first twenty-four hours; and when the metallic oxide was introduced by a wound in its bark, a lilac-tree fell a victim very slowly to its agency. Now it fares with insects as it fared with those plants, due allowance being made for their smaller size, and the greater activity of their circulating fluids. I made experiments with a variety of agents; arsenic, concentrated acids, strychnine, hydrocyanic acid, and the juice of the Agaricus muscarius. The insects selected were principally beetles, and the results obtained were as follows :none of the above-mentioned agents took immediate effect. The larger the insect, the longer was the poison in acting; one Calosoma, or Procrustes, outlived two small Harpali, or Amaræ, of the same family, poisoned in the same way. The more active the kind of beetle, the sooner did the poison begin to take effect: thus, of three very different tribes, the predatory beetles (whose activity is unmatched in the insect reign) died with comparative rapidity, under the effects of the same agent, which, in Longicoms of similar dimensions, occasioned death much 
more slowly, and which, when applied to Melasomes, (who live in cold, dark places, and whose movements are exceedingly sluggish,) was still longer in destroying life. When the poison was not taken into the stomach, but was artificially introduced under the corselet, its agency was slower than when it had been taken in by the insect with its food; thus the juice of the "Agaricus muscarius," when it was swallowed in syrup by flies, killed them sooner than when it was introduced through a small incision in their corselets. These facts, while they discountenance the supposition of a "centrum commune," seem explicable by the greater or less rapidity with which the poison is carried through the system: this again depending on the comparative rate at which the vital fluids, in the several tribes of insects, move through their bodies.

We have seen above, sufficiently at least for our purpose, how the insect in general is composed, and how unfavourable his composition is to the popular supposition of his sensibility. The next part of our enquiry contemplates him alive, and in the exercise of his various acts ; but as too many examples would only be tedious, I shall select a few instances, and leave the reader to prosecute the research. For this purpose let us seize upon a Grillus, and put him to the question-liere he is! his antennæe 
waving to the breeze, his glazed eyes fixed on vacancy, and ready for any thing he can find in the way of employment for the millstone machinery of his jaws! Entertaining no doubt of his impassive nature, we have no scruple in depriving him of a leg, nor does he seem to mind it; no sympathetic movement takes place in the remaining members; neither the trunk nor the wings are agitated; and in a moment we have the satisfaction of seeing him squatting quietly on our hand, as if nothing particular had happened. As to his pose, if you would take a portrait of him, his remaining leg is doubled under his belly, and his jaws are moving as before. If you now present him with the extremity of the separated limb, he seizes it between his teeth, and in less than five minutes has broken the shell, and picked his own thighbone, close up to the joint! Bend back one of his antennæ into his mouth; and it fares with the "feeler," or organ of touch, as it had fared with the organ of motion; he is actually biting off the instrument which Nature gave him to feel his way with, till the mutilated stump can no longer be brought within the range of his voracity ! But these wonders are inconsiderable to those which occurred to a brother-collector, who, having caught numerous specimens of a pretty kind of grasshopper, proceeded to put them into a condition for preserva- 
tion. Accordingly he removed their insides, filled the cavity with cotton and camphor, sewed up the sides of the slit, and completed his job by running a pin through each insect, fixing him finally, as he flattered himself, on a board, to dry at leisure in the sun. In about an hour he returned, but his family of grasshoppers were gone! the board was clear! not one remained to tell what had become of the rest! Search being made, our friend was astonished to find a part of them assembled round the plate on which their own intestines had been deposited, and the party actually, and unmistakably, engaged in tasting them! The reader, if he be not a collector, is no doubt suitably shocked, or as much so as his incredulity will permit him to be; but any entomologist will assure him that such marvels are not solitary. One gentleman tells me that he has seen in his shrubbery a mutilated cockchafer, without either elytra or abdomen, still firmly adhering by his feet to a leaf which he was eating; another found that a flea, from which he had removed the body, still fastened on his hand, and was actually sucking his blood, though the organ to which it should have been conveyed was gone. But De Geer's experience of the conduct of the "Ptinus pertinax," under a great variety of bodily injury, is still more remarkable. "Having once drawn up his legs, nothing will 
induce him to stir; neither fire, nor water, nor torture of any kind, however cruelly devised, ever provokes one movement of impatience. Right well does he maintain the name of 'Pertinax', which his extraordinary determination has procured for him. I have frequently held a few specimens of his family in a spoon over a spirit lamp, and though the metal was gradually warming under their bodies, and though nothing was easier than for them to have escaped over the side of the spoon, not one stirred a foot; all permitted themselves positively to be roasted over a slow fire: they seem in short to have died, and 'made no sign." De Geer attributes their conduct to excess of courage!! It may seem a more natural solution to many, to attribute it to a deficiency of sensibility. The scorpion notoriously attacks his own body, but whether it is in hunger or in rage is not yet a settled question among the authorities; the "Locusta viridis," the "Lamia textor," the "Lycosa tarantula," confined for a few hours, although food be supplied to them, will do the same; and I have been informed by a friend, who watched the proceedings of the last of these insects under incarceration, that one night he deliberately took off his own legs. I have myself seen the Lamia textor, under similar circumstances, deprive himself of one of these members ; and the larger kinds of 
grasshoppers not only treat their extremities in this way, (though no insect should better know the value of his legs,) but, having detached, they afterwards eat them. If a spider's leg be removed from his body while he is sitting in his loom, he hardly winces at the moment, nor attempts to escape by climbing, but remains with the others stretched out, as before. If the "Opatrum sabulosum," having his legs doubled up under him, be transfixed with a pin, he remains immovable as before. The "Dermestes," in carrying on the joke of pretending, as it is said, to be dead, values his reputation as an actor so much, that he will not stir till he has been nearly pulled to pieces. Put sugar in the way of a mangled fly, and he cannot resist it. A young collector will often be startled on opening a box of insects from which to take recruits into his own, at observing, among a hundred and more, apparently dead, one specimen come to life, and then another. Surely an insect which, after being steeped in spirits of wine for many hours, dismembered, or even embowelled, spontaneously returns to life, affords irrefragable proof of his having been intended for a mode of existence exceedingly unlike that of a sentient creature. The "Blaps," (Reaumur,) the Akis, (Cuvier,) the Calasoma auropunctatem, (Lemaint, ${ }^{*}$ ) who live for

- Dr Lemaint relates the following anecdote respecting this 
six or nine months, or for two years, fastened to a cork-tablet on a pin, do not assuredly possess that "sensible warm motion," which should perish before a very small part of the mal-treatment which they have undergone.

And now, in place of committing further acts of violence upon insects, let us look at their conduct in their everyday life. Some of them, no doubt, do shrink from the touch. But though the caterpillar, meddled with ever so lightly, will move briskly'enough to raise a suspicion that his sensibility is annoyed; though the spider may, without poetry, be said to "live along the line," and pass for the most tetchy of created things; and though the slug, on being handled, will, as if in defence of his skin, pour out slime in abundance; yet this very writhing caterpillar, this slime-defended slug, this all-sensitive spider, are seen running, or crawling over, or committing

insect:- " Poor Le Doux, six months before his death, brought me a small box; opening which, he showed me an insect that had already lived upwards of a year, transfixed upon a pin; telling me that the beetle had still more life in him than he had, ' for,' said Le Doux, 'he eats and digests, while I am dying of cancer of the stomach.' Six months after our interview, Le Doux was no more! His insect was, by his orders, brought to me, with instructions as to how I was to feed him; after this I kept him alive for upwards of six months, feeding him upon caterpillars, which he seized with great adroitness, straining to reach them from his pin." 
ravages on, the stinging nettle, (a plant which, by the way, is so great a favourite with insects, that it has at least fifty kinds of pensioners of its own to board and lodge ;) but, if the barbs of the nettle penetrate and wound our comparatively hard integuments, $a$ fortiori should they annoy the soft epidermis of these insects, if that epidermis could feel ; of this, however, they do not afford even the doubtful evidence of quickened motion, since there is no flinching in their progress over such irritating materials. One might have been prepared, indeed, for the caterpillar's indifference, even to the penetration of the collector's needle, by the remarkable fact in his natural history, that he does not so much as wince under the forcible entry of the Ichneumon's ovipositor, with which she penetrates his skin, to inoculate it with her pernicious eggs. Nor do acrid juices of the sharpest kind rouse the sensibility which mechanical stimuli fail to evoke ; for many insects feed on euphorbias, on milky agarics, on arums, and other plants, the juices of which resicate our skin, and would presently inflame the mucous membrane of our mouths or stomachs.

One of the commonest prejudices arrayed in favour of insects' sensibility, already combated briefly above, must now fall under fuller and more formal discussion, while we enquire, whether the motions which 
they exhibit under stimulation, the contractions into which the bodies of some amongst them are sometimes thrown after injury, are to be regarded as so many proofs that they suffer pain. In the first place, had there been no such creature as a worm, we should perhaps never have heard of the argument from motion at all; for it is only in animals of that construction, that the wriggling or writhing motion, on which so much has been founded, takes place. Yet a single case, and that single case misinterpreted, can hardly invalidate our former conclusions. A decapitated snake moves after the same fashion, as if his nervous centre was entire. The twisting, supposed to express pain, in the whole worm trodden on, with his organ of sensation (if there be one) entire, occurs equally in the pieces into which he may be cut. But in reality no kind of motion proves pain. In our own bodies restlessness, and the tossing to and fro of the limbs, may be evidence of disturbance, but not necessarily of pain, or injury of any known part; and in the worst pain our frame can endure, (that of Tetanus, it is rigid immobility that coexists with intolerable suffering; while chorea, on the other hand, a sufficiently violent disorder of the organs of motion, is entirely painless. There is not even plausibility in the argument. Yet there is the eternal case of the worm, whose contortions, like 
those of the begging impostor, seem all devised to beguile us into a mistaken sympathy. We read, even in physiological works, of "movements expressive of pain," unscrupulously applied not only to insects, but even to amorphous masses of sponge and polype! Why, plants exhibit movements, which, did they not occur in vegetable matter, might be put down to pain. "In the oscillatoriæ," (a kind of Algæ,) " the filaments have a movement of alternate flexion and extension, writhing like worms in pain; sometimes they appear to twist spirally, and then to project themselves forward by straightening again." * Movements in this department of nature at least, of whatever kind, are necessarily unattended with consciousness or sensation, yet many of them are so remarkable, that the ingenious author of the article "Algæ," in the "Penny Cyclopedia," considers them as sufficient to disturb the proposition, that spontaneous locomotion is an infallible test of animal life. Captain Carmichael Smith found that some Confervæ oscillatoriæ in a watch-glass, moved their limbs and travelled so fast, that, in a few hours, they had accomplished a journey of ten times their own length; the spores of other Confervæ, after running about their tubes for some time, will jump into water and swim about, until, finding a shady place in which it

" “Carpenter's Physiology," page 425. 
suits them to abide, they there send out roots, as if they had at last made up their minds to pass the remainder of their lives in repose, like other vegetables. Of the disjointed Algæ, (motionless while whole,) the separated portions acquire a distinct starting or sliding motion. The pollen-grain of the "Asclepiada" is packed in bags, without any apparent means of escape at the time of impregnation; each grain of the pollen thus disposed of, sends out a little tube towards the side of the bag, which it pierces, and, in order to reach the stigma, pursues whatever direction may be necessary for so doing. Of the common "Broom," the "males, or stamens, are produced in two sets, one set rising half an inch above the other; now, the upper set does not arrive at maturity so soon as the lower, and the stigma, or head of the female, is produced among the upper, or immature set; as soon, therefore, as the pistil grows tall enough to burst open the leaf, or head of the flower, it bends itself round in an instant, like a French-horn, and inserts its head, or stigma, amongst the lower, or mature set of males. The pistil, or female, continues to grow in length, and in a few days the stigma arrives again among the upper set by the time they are mature."-(Darwin.) The Desmodium gyrans of Bengal has also its spontaneous motion, which seems quite independent of exter- 
nal stimulus. "No sooner has this plant acquired its ternate leaves, than they begin to move in every direction, unobservant of order, time, or duration; sometimes a few leaflets, sometimes the whole plant, moving at once, during night and day, in light and darkness; the two side-leaflets move incessantly; they describe an arch forward towards the middle leaflet, and then make towards the foot-stalk; revolving thus on their articulation with the petiole, they pass over the space in thirty or forty seconds, one usually rising whilst the other is sinking-the inflection downwards takes place the most rapidly, and by starts, like the motion of the hand which marks the seconds in a stop-watch." Michale, the great authority on funguses, describes one species which, from its projecting its seed into the air, he calls the "Carpobalus;" but the behaviour of the "Valisneria" affords a more particular temptation to call upon him as a witness. His deeds have been recorded in poetry, sufficiently accurate to be quoted (by Dumeril) in a book of science :-

" La Rhone impétueux, sous son onde écumante, Durant six mois entiers, nous dérobe une plante, Dont la tige s'allongeant, en la saison d'amour, Monte audessus des flots, et brille aux yeux du jour. Les males jusqu'alors, dans le fond immobiles, De leurs liens, trop courts, brisent les nœuds débiles, Voquent vers leurs amantes, et libres dans leurs feux, Leur forment, sur le fleuve, un cortège nombreux, 
Mais le temps de Venus une fois accompli, La tige se retire."

The following account of the movements of the Nostoc, with which I shall conclude, was given me by Dr Gorgone, Professor of Anatomy at Palermo, showing that every kind of motion may be practised by plants as well as by animals. " Having collected specimens of the various Nostrochinæ which grow in the immediate neighbourhood of my house, and having taken every precaution to prevent them from being shaken or disturbed, I proceeded to examine them under a microscope. My experiments, which were continued for several months, furnished me with the following interesting results. The filaments, when they began to move, took sometimes the same, sometimes an opposite course; some, which were at first straight, would bend themselves into a great variety of shapes, while those which at first took the form of a circle or crescent, or were twisted like the letter $\mathrm{S}$, suddenly straightened themselves while I was looking at them. Some of the filaments ran to meet others, to which they immediately attached themselves, either lengthways, or by winding like tendrils round them. Others, which had been intimately, and, apparently, inseparably connected tegether, would untwist themselves, and again become free. Some, after lying for a time horizontally, 
would erect themselves like snakes, and stand vertically. Finally, I remarked that the Nostoc would occasionally move half, or a portion of its body, while the other part remained quite still." Nor are we confined to plants. Many infusoria exhibit movements enough to justify a suspicion that they have feeling also, if motion and feeling are inseparable. "Some infusoria," so writes their historian, Ehrenberg, "swim with the velocity of an arrow, so that the eye can scarcely follow them. Others, perfect reptiles in their progression, drag their bodies along with difficulty-some move like a leech-some revolve round the centre of their bodies on the crown of their heads-some waver in perpetual oscillations -some leap ; nor is there any kind of animal motion, or of progression, which is not practised by these animalculæ."

It is impossible to limit the speculations of fanciful writers on a favourite topic, or one would have thought that, had there been a single undisputed point in all physiology, it would have been this - that where there are no nerves, there can be no sensation, and where no sensation certainly no will; yet it is still propounded, in the form of an unsettled subject of enquiry, whether the gemmules of polypes and sponges, whose power of locomotion is thus remarkable, but whom Aristotle had declared to be in all 
respects like plants, really accomplish such locomotion "by a voluntary act, or by a force with which their structure is furnished." Can modern physiology really lend her sanction to the supposition, that a brainless and nerveless structure is able to feel, or be a voluntary agent? for, to press what has been already said, of what quality, or endowment, in animal bodies, is motion of any kind the evidence? Surely of that kind, and that only, which, residing in the muscular fibre, is called "Irritability ;" a quality which, even in cases where they had existed together, is well known to outlive sensibility. The convulsions of a frog's leg, after it had been separated from the spinal cord, surprised Galvani into his discovery of a new agent; that agent has been employed to throw the dead body of a man into violent convulsions through its whole extent-an experiment, whatever else we may think of it, surely not reprehensible on the score of humanity; feeling being out of the question. When palsy has wholly removed the limb from the nerves of sensation, and from the will of the party to move it, the prick of a needle on the sole of the foot still produces movements, but they are movements of which he is unconscious. As neither will, nor sensation, are the efficients of motion, so neither are will and sensation necessarily attendants on it. When will and con- 
sciousness are suspended by sleep, the somnambulist walks; and limbs benumbed with catalepsy will exercise muscular force in retaining a position alien to repose, if they have been placed in that position. Sensation is not essential to life; but motion, of some sort, appears to be so. The limpet and the oyster, though fixed upon the rock, must open and shut their shells; and even the oak must wave his branches, under the penalty of his fluids becoming lethargic and of his heart mouldering away! The motions of insects are required at the very commencement of their life, for the due expansion of their wings, to help them out of their pupa state, to enable them to cleanse themselves, and so forth.

On what ground, we ask, is sensation so zealously asserted for insects? Is it not a more pleasing reflection that they are exempt, by wanting it, from the manifold pains to which their helplessness and their countless swarms would otherwise subject them? And if it appear, at first sight, an unpoetical creed which would rob them, together with suffering, of enjoyment, we should remember that it is the very vocation of poetry to endue outward things with hues borrowed from our inward feelings, and to invest nature with a life which is not properly her own, but is a reflex of the mind of Him in whom the 
very flowers of the field rejoice, and all things love and embrace each other.

"We do receive but what we give, And in our life alone doth Nature live."

As we may conceive of a given form without colour, but not the reverse, so a sensual notice, unaccompanied by any perception of pleasure or pain, would be quite intelligible even if it were not a matter of daily experience; but the conditions called pleasure and pain, without an accompanying image of some quality of the outward world, are inconceivable and impossible. For, if we were to take the case of a creature endowed with no sense beside that of touch, we should still be obliged to suppose some condition of temperature, or some adaptation of surface, or some fact of a like kind, as the ground of its painful or pleasurable affection, and this ground would be so much knowledge conveyed to the sentient animal. Even the pains and pleasures which arise out of the general sensibility, as contradistinguished from the sense of touch; viz. aching, tickling, and the like, are accompanied by so much knowledge-for we refer them to a determinate seat. The same condition, too, will occasion both pain and pleasure, according as its amount is moderate or excessive; so that here the pain or 
pleasure is separable from the process itself; and accordingly, if we separate them in our conception of the process, the residuum will be a fact; and the mental faculty will receive that fact as such-that is, will have knowledge. The general sensibility is admitted by all physiologists to be distinct from the sense of touch, and it is impossible not to assent to the truth of the differences which they have pointed out between the two. But that it is a sixth sense, as those would make it who give to it the name of touch, (reserving that of tact to the function which the fingers and the lips are principally employed in performing,) or that the pleasure and pain with which we find it accompanied in our own case, must necessarily attend upon its exercise in all animals to the same degree, are matters of another kind, and demand other proofs. For the maintenance of the former assertion, it is necessary that one should point out-some distinct set of nerves, to which this province is assigned; while the improbability of the latter will perhaps appear, from what will be said further concerning pleasure and pain. In the instance above supposed, of a creature without any sense but touch and general sensibility, it would be impossible to determine the primary intention of the Giver in bestowing a gift of a twofold use. But comparative anatomy neither knows, nor admits of, a 
creature thus endowed. Wherever there is a brain; and consequent sensibility, there are always several organs of sense ; and the variety of the senses themselves declares, at once, for what end they are given ; for knowledge of things outward is a knowledge of differences, as Aristotle has remarked; and that which is so arranged as to convey the greatest possible number of differences, is contrived as an engine of knowledge. Pleasure and pain may be much higher ends, in themselves, than any sensual notices or perceptions; but even if they are, this will only show that the accidental end is greater than the essential; and I know not why this should be thought improbable. At all events, many brute creatures possess a nicer sense of hearing, or smelling, than man; but all observation warrants us in saying, that no creature can be matched with him in the readiness, and the accuracy, with which he pronounces upon the agreeableness or disagreeableness of sounds or smells. The dog, whose nostril detects the faintest differences in the minutest quantities of odorous matter, has yet no such repugnance to some smells, or affection for others, according to the nature of each, in itself, as we have; his preference seeming to be altogether regulated, not by the suitableness of the quality to the organ, but by association-i.e. by suggestions of the object of his appetite 
or his pastime. That the same rule, which we may clearly ascertain in several instances of sight, hearing, taste, and smell, must hold good in the case of touch also, is shown by the examples of the rabbit and the pigeon, adduced above. But when we come to an animal who is made to converse, not merely with impressions, nay, not even with things, but with a world, (the world of eye and ear, indeed, but emblematic of the world of reason and of spirit,) the lessons of the senses become more emphatic, as their purpose and moral are more sublime. Pain and pleasure are, as it were, * the morality of the brute creation: the one ratifies, the other condemns his choice, according as it is wisely or foolishly made. The brute never attends to his pleasure, or challenges his pain; he never grapples with their nature, or investigates, or disputes, what hold they have, or ought to have, upon him. The state of which they are the opposite extremes, is his appointed state, and therein he must acquiesce. But on man, the good and evil of animal life have no power, further than is required

* Insensibility to pain, or indifference to pleasure, are defects in man, except when they are the result of the exertion and cultivation of some higher faculty. The most refined man is the most acutely alive to both, though he also possesses the readiest and most potent means of defying both upon occa.

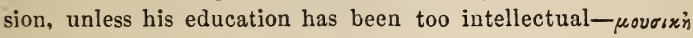

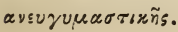


to rouse him to the assertion of himself; for it is in this opposition between man and his inorganic nature, that the rudiments of his moral education consist: it is the first of the two epochs of that great process by which he reaches the very highest point of Finite Being. For it is by the assertion of himself against all that is outward, that he arrives at the assertion of his permanent and hidden self, against his visible and transitory nature; and the education of appetite into passion, must precede the education of passion into moral purpose.

I will not trust myself with this theme any further, but shall be content with remarking, that the wellbeing consequent upon the attainment of any end, is in proportion to the greatness of the end attained. A small exercise of will, in a right direction, is attended by only a slight satisfaction. In the case of intellectual pleasure, all men who learn have a satisfaction in learning, but few can cry

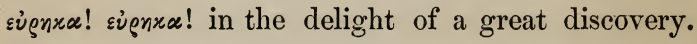
The wellbeing of the sensitive faculty or pleasure, properly so called, must, in accordance with this analogy, supervene, not so much when any particular organ is nicely endowed, and meets with its appropriate object, as when the whole faculty is at the highest. The prerogative of man is voluntary activity, as contradistinguished from activity called forth by 
previous impression, and manifests itself in present sensations, as attention-in past, as recollection. Brutes only remember; that is, keep their past impressions in store against the recurrence of any similar ones; and these suggest those others immediately, and without the consent or co-operation of the individual. But man alone recollects; that is, recalls his impressions without suggestion, though even in this case the process depends on the law of association. The mind, in its active state, connects according to resemblances, but the resemblances are of its own seeking: this state, therefore, is not so favourable to the reproduction of all that lies dormant in the memory, as a state of lower activity, or merely passive sensibility. It is in the latter that we meet with those marvels of memory which are recorded of the bird and the beast, and sometimes of the entranced or sleeping man. A pigeon will remember his nest; a dog who has been scourged, the whip. A horse will remember the road he has once travelled, better than his rider. But what equals in wonder the story of the servant girl, who, in a state of catalepsy, repeated passages from Sophocles, and from the Hebrew prophets, which she had never learned by heart, and of which she was utterly ignorant in her waking state? She had been in the service of a clergyman, who had a habit of repeating 
these passages aloud, and they had settled into her memory; but, as they had been acquired without attention, so they were not within the reach of recollection; but when all spontaneous action of the mind had ceased, they reproduced themselves in the order in which they had been imbibed. It is unimportant, in a matter of such common notoriety, whether the instance quoted is true or not. I have chosen this example as the most illustrative; but, though believing, I will not vouch for it. Stories are related of persons in a trance speaking languages of which, when conscious, they had forgotten every word. All such examples are the opposites of those in which the activity is so strong that the memory is completely obscured, as in nervous hesitation, anger, eagerness, and so forth. What wonder is it, then, if that which causes such a difference between man and brute as the nature of their memories, exerts a like influence on sensation? The power of entertaining a sensuous image, or of abstracting the mind from it, is one which cannot be questioned in man, or vindicated for any other animal. The senses of the latter are rather handles which they present to nature, that she may act upon them, and dispose of them as she shall herself determine, and not instruments wielded by the possessor for his own purposes. The ape, when affronted, 
will chide and chatter, as though he had the deepest sense of indignity; but at the highest pitch of his resentment, the offer of some new object at once attracts his curiosity: he forgets the affront and the author of it together, and is absorbed in his new plaything while its novelty lasts, or until a fresh impression invites his mind in some other direction. The dog will seem to stare affectionately in his master's face, but he soon turns away his eyes, and fixes them, with equal complacency on vacancy. Brief and soon forgotten impulses are all that the senses yield, except in man.

The apparatus of sensation is a marvellous instrument, but in the brute the hand of the player is not there to combine and harmonize the sound; the notes which it utters are as fitful and irregular as the restless changes of those sensible elements that call them forth. With such a difference in the meaning and purpose of sensation, as displayed by its practical use, how much must the amount of pleasure and pain in the brute be inferior to that which we ourselves experience? The hypochondriac, who voluntarily dwells on uneasiness until, to his disordered sensibility, it becomes an intolerable pain, differs from the sleeping man, who is almost indifferent to the pinching with which one endeavours to awaken him, in the very circumstance in which 
the human sensibility differs from that of the dog or the ape, namely, in the presence of voluntary attention. I say voluntary attention, because there is a forced attention, which may be witnessed in the irrational animal under the effect of a deep and engrossing sensation, and also because, from all that has been observed above, it is evidently not a faculty, but a state, or habit, produced by the direct and immediate agency of the will of the man himself, or the sensitive faculty which he possesses. Since the capacity of feeling admits of degrees, and those degrees are regulated by the amount of other and greater faculties coexistent with it, wherever the lowest form of consciousness stands alone, there its office will be confined to the merest and barest record of what is going on without ; it will differ from all higher states, as a meagre chronicle differs from a reflective history.

To apply the foregoing remarks to the question of insect sensibility - it being admitted that all animals do not feel alike-it will be conceivable that animals of the lowest order do not feel at all ; and the objection, a priori, being removed, the authority of comparative anatomy, as sufficient to determine the question, and alone capable of so doing, will be readily admitted. But the more clearly this is recognised, the more necessary it is to use all 
diligence in exploring the anatomical features of the insect, and in investigating how far the foregoing statement concerning its general constitution, agrees with what remains to be said of the organization of its different parts. Mention has been made of eyes and of antennæ. If these eyes are rightly so called, or if the antennæe answer the purpose of touch, or, in short, if there be any trace of a separate organ of sense, then, notwithstanding all that has been said above without doubt we shall not be justified in refusing that faculty to the insect, of which he possesses the acknowledged instruments; nor can we deny that, having the formal instruments, or apparatus of pleasure and pain, he may be a partaker in both, though to what extent cannot be ascertained. But if, on the contrary, it can be shown that what has been called an organ of sense is misnamed, and that, in going through the list of the senses, we are able to refuse each, in succession, to the creatures under discussion, all that has been alleged before derives a tenfold force, and the proof is as complete as science can make it.

I shall begir by challenging the sense of touch. Of this sense the appointed organ is the skin, but the skin under certain healthy conditions; for not only this, but every organ of a special sense, is de. pendent for the exercise of its functions on the nor- 
mal condition of those tissues in or near which it is situated, or of which it is composed; that is to say, irritability is the condition of sensibility, and a surface in which the former is extinguished is incapable of the latter. Irritability and its changes furnish a large portion of the objects on which the sense of touch is exercised; and it is to express, though in a very clumsy manner, this distinction between the different provinces of that sense, that physiologists have applied the word touch to this general sensibility, as they suppose it to be, (though I should rather have said this condition of general sensibility,) and have invented the new and infelicitous name of tact, for expressing that sense which distinguishes the surfaces of bodies. But, at all events, whether this doctrine of a sixth sense be or be not admitted, it is certain that a susceptibility to the stimulus of chemical and corporeal agents, and of heat and cold, resides with, and is the necessary condition of, each particular organ of sense. Many writers, indeed, have been tempted by the invariable appearance of this condition of the organs of seeing, hearing, tasting, smelling, and touching, to advance a theory that this so-called general sensibility of the organ is a portion of the functional sensibility, and derived from it; but it is well known that it may, in disordered states of the system, be affected to a consider- 
able extent, without impairing the perfection of the sense itself. The function of the auditory nerve may remain unimpaired under the most violent ache of the miembrane which lines the ear. Vision is not destroyed by incipient inflammation of the retina; and though the increased sensibility of the schneiderian membrane in a cold is attended with a diminution of the sense of smell, it is only because the membrane is thickened, so that the volatile particles in the air have no longer the same free access to the expanded nerve. The particular senses are so far independent of the diffused sensibility of the organs which administer to them, that the sense, or particular office of the nerve, may be lost, while the sensibility of the external structure remains. In amaurosis, or extinction of the visual power, the general sensibility of the retina is retained; the ear which has lost its hearing may ache; both taste and smell have been nearly abolished without, in the least, impairing the common sensibility of the mucous membrane of the mouth and nose. The first and second of these instances are of familiar occurrence, and I have myself on two occasions met with examples of the third. But the reverse will by no means be found to follow: we have no experience of the ear, the eye, the palate, or the nostril, carrying on their peculiar functions after the general sensibility of the tissues 
has been extinguished. In touch, we have positive experience to the contrary; a skin on which stimuli would fail to act-a skin which could neither smart, ache, nor be tickled, (I use these words, though they imply touch as well, in a more limited sense, as the conditions in the irritable structure which furnish these conditions,) ceases to be the organ of touch, as we see it exemplified in the effects of intense cold, which, by depriving the surface of that blood which supports and vivifies its subtle organization, numbs the general sensibility, and at the same time paralyses the particular sense, while an increasing. warmth communicates to the over-sensible skin an increased nicety in the fulfilment of its office. If, then, an highly organized tissue can, through the withdrawal of some of the conditions of its healthy state, become utterly unserviceable as a means of distinguishing the surfaces of bodies, what shall we say of integuments, which not only do not wince under the poisoned barbs of thistles and stinging nettles, but which in many instances carrywithin them, and are full of, liquids so caustic, that we employ them for the vesication of our own skins? and though the induction is but partial, the objection will apply universally ; for who would dream of granting to one insect what he denied to another?

It is the more important to attend to this, because 
many esteemed writers on entomology-though forced by the conduct of an insect, when injured, to admit that he shows small evidence of general sensibility - have yet, when their subject brings them to speak of touch in the abstract, made it the great instrument by which the wonders of insect architecture are accomplished. Thus, although unable, from what they see, to impute much general sensibility to the spider, they yet assert that the delicacy of his touch is displayed beyond the possibility of doubt; and that the fact of his working his nets with his hind-legs, and in the dark, indicates that this sense, being the only one which he can turn to account, possesses an additional portion of accuracy, in compensation for the help which it would otherwise have derived from the sense of sight. Now, this is certainly an inconsistency; but the after assumption which is resorted to for a particular end, does not invalidate the previous admission. Whoever contents himself with simply recording what he sees, and does not go out of his way to suppose a power of which there is no evidence, in order to explain, and that very inadequately, the marvellous works of bees and spiders, will admit, that as insects give very equivocal signs of any diffused sensibility, their possession of the sense of touch must be proportionally obscure; while the exquisite degree of 
it which has been pretended, must be seen to be utterly unfounded. And yet this is the favourite sense with entomologists, and the one to which they refer almost all the operations of insects;-by touch alone, by the mere crossing of their antennæ, ants are said to deliver themselves of matters arising in the conduct of their affairs, to record which whole sentences are required; while the tactus eruditissimus of bees discerns the presence, and apprehends the mandates of their queen. To what purpose is all this waste of suppositions? The geometrical figure of the web or the cell, the activity of the makers of them, sustained until the completion of their taskall in the wonder that is most wonderful, remains as unexplained as ever !

\section{SIGHT OF INSECTS.}

He that would assert the title of insects in general to the possession of this sense, is already in possession of two important arguments to start with. An organ can be pointed out in which to lodge the supposed faculty; and as that faculty is, from analogy, the most useful of all the senses, it would seem an anomaly that an intelligent creature (the intelligence, however, being entirely assumed, and for 
the present unchallenged) should have been created without it. The greater number of insects, then, must be admitted to have what most physiologists would call eyes; but whether they are properly so called, can only be fully determined by the function they exercise, in enquiring into the exercise of which, it may, perhaps, be not very difficult to show, that they differ entirely from organs of sight as we possess and understand them.

Light is an universal stimulus, not only to the brain and nervous system of animals, but also to the unsentient organization of plants ; it may therefore, as in the latter case, be an appropriate stimulus to insect existence, without conferring sight in the way in which man understands and enjoys it. Let us here consider, for a moment, the conditions, on the fulfilment of which the sense of sight depends. First, there is the connection of the eye with its optic nerve, and of the optic nerve with the brain. When the connection is interrupted, as in certain diseases of the brain, or by pressure on the optic thalamus, or along the course of the nerve, blindness asinevitably follows let the humours of the eye remain ever so transparent) as when, in cataract, the brain and optic nerve remaining sound, the crystalline lens is opaque, and the rays of light are mechanically excluded. These conditions are therefore necessary to vision-an eye with 
its optic nerve, a brain, and a sentient principle. How does it fare with insects in these particulars? What sort of eyes have they?-for most of them have eyes, such as they are, and some have them beyond the allotment of the fabled Argus. As to their kind, some insects have what are called stemmata, for vision upward; some, as bees, have facetted eyes, for vision horizontally, or downward. Spiders have eight eyes, distributed over their heads. In the two eyes of a dragon-fly, the microscope of $\mathrm{Dr}$ Hook enabled him to count 1400 facettes, each facette being an eye in itself. Liewenhoeck computed 12,544 in another species of the same fly. Ants, and common butterflies, are also in possession of a large provision. If the transmission of light through a beautifully diaphanous cornea were the only conditions required for sight, these facetted eyes of insects would be perfect. Puget having adapted the eye of a flea to a microscope, converted a single soldier, seen through its numerous facettes, into a battalion of Lilliputians, and enjoyed in the light of one candle an illumination of ten thousand. Through the eye of a Libellula, similarly adjusted, Liewenhoeck distinctly saw the steeple of a church 300 feet high, at a distance of 750 feet, and of the doors and windows of a house, could distinguish which were open and which were shut; all showing 
the perfection of so minute an organ, in relation to the transmission of light and the extent of its field of vision-so much for the organ. Many of the actions of insects, on a first view, seem also to be the result of vision. The bee flies straight to the hive, like a falcon to his prey. But if insects want a brain, "stemmata quid faciunt?" Of what use are eyes? Eyes existing as they do alone in many creatures, without any nerves attached to them, or eyes dispersed over different parts of their bodies, and as near to the bowels as the brain, if there were one, do not prove vision. The Polygastrica have eyes of this sort, which must necessarily be sightless, though obviously intended to let in light, and to stimulate the irritability of the animal economy. In the Conchifera, such unconnected eyes are so many studs round the corselet, " affording" (says Dr Carpenter) " an interesting link between diffused sensibility to light, which is probably possessed by the whole of the surface in the inferior tribes, and the proper sense of sight." Work is executed by the caterpillar, which an intelligent weaver would say required an " all-eyed attention;" but the caterpillar has no eyes. Some kinds of ants which live in the earth, are so disagreeably influenced by light when brought out, that if there be a mode of covering themselves, they have recourse to it. The eyeless worm, as every 
angler knows, is very susceptible to light; so that if, on a moist night, a candle be brought to a mound of earth covered with these creatures, in an instant they all disappear, nor can they be brought out of their subterranean tunnels in which they take refuge without a spade. But, says the objector"You choose your instances. Take a spider's web, or a bee's cell-here, surely, the architects undoubtedly have eyes, and make good use of them." The answer is immediate. The bee constructs these wonderful hexagonal cells in darkness ; for the hive has no window, and the lynx-eyed spider does his geometry in the night-season-nay, his spinnerets, unlike those of the silkworm and caterpillar, are generally behind him, so that he cannot direct them by his eyes. It must also be taken into account, that the eye does not begin with a faultless execution even in man; it judges of distances entirely by experience;-it must be educated, or it would remain an organ only to mislead: touch and sight, therefore, most usefully go hand in hand, and check each other in teaching us the relative distances, and other properties of objects. In Cheselden's oftenquoted case, the boy, on first receiving his sight, had no idea of distance. When he first saw, he was so far from having any judgment about distances, that he thought all objects whatever touched his 
eyes, in the same way as what he felt touched his skin; he knew not one thing from another, however different in shape and magnitude. But the bee is no sooner in possession of his eyes and wings, than he is off to use them! He makes no mistake, but flies straight on his business, and returns honeyladen, and uninjured, from the very first voyage of discovery; his conduct throughout his whole excursion giving every reason to doubt, whether his flight be guided or regulated by vision. The eyes of such a creature as the "Hepialos," * who destroys himself, as by an irresistible impulse, in the flame of the candle, are assuredly more likely to be inlets for the stimulus of light, towards which the creature exhibits so great a tendency, than organs of vision, which, in this case, would have been bestowed in vain; for to what better end than the avoidance of danger, can any sense be supposed to minister in the irrational subject? In this latter case, at least, I cannot help agreeing with Mallebranche, "that the senses are not given for the sake of mental improvement, which they sometimes impede; but for the safety of the animal machine, by apprizing the indi-

* The Byzantine Greeks called them the "Extinguishers," because they used to flock around the lamps employed on festive occasions in such myriads as to put them out, and leave the guests "senza moccoli." 
vidual of impending danger." In the instance of the moth, however, we look in vain for the service which this so-called organ of vision is supposed to render to its possessor. But it will be said that a fly, with his microscopic organ, plainly sees you, for he will not let you touch him. Is he then afraid? By no means; for he shuns you before he can be aware of your bad intentions, and not from experience of them. Besides, if his vision makes him fear you in spring, why does he not fear you in autumn, instead of haunting you with such tormenting assiduity? If a fly fear you, with how much more reason ought a flea! and we have seen above of what the eyes of a flea are capable. An ant is said to have more wit than a fly; and yet, if you walk in a wood, the pismires will stick upon you in all directions. As long as so many insects crawl over us fearlessly, we cannot think the avoidance of others proves that they see us. The Cicada derives no safety from her eyes; for, as Aristotle relates, "she mistakes your hand for a leaf in motion, flies to it, and is caught." But how shall we account for the clustering of bees round the door of their hive, while fresh ones are coming in every minute? How, but by attributing eyesight to them, can we account for this gathering, and this determined action of their flight to a single point? Yet not assuredly by 
eyesight alone, unless we can also suppose that faculty of the mind, called attention, exercised too in no inconsiderable degree. A thousand objects are continually depicted in our own retinæ, which, unless we give them our attention, are to us as though they were not; so, though the hive be painted on every facette of every eye of the bee, unless he has a mind capable of attending to these visual impressions, the hive does not exist to him. But the spider crouching "in grim repose," and watching for his prey, who sits for hours amidst his gossamer meshes, ready to spring on the first fly that shall venture into that treacherous arrangement of threads, seems on the look-out, if ever sentinel did; yet no one can imagine that a spider has a mind capable of that fixed and fatiguing attention, which is probably the exclusive privilege of man, and which cannot be presumed to exist in creatures thus infinitely below him in the scale of creation. Besides, a young spider, before he can have seen a fly at all, or can know what it is, puts himself in the same attitude of expectancy. But it may be said, that though a spider may not in fact be watching with premeditation for a fly's body, this does not prove that he cannot see his prisoner when struggling in his net. How, it will be objected, except by sight, can the hunting spider, which has no net to inform his fingers by 
touch of the presence of something in the trap, pounce upon his victim?* To all objections of this kind, it is fair to reply, that as the difficulty is not removed by supposing sight-a concession which only shifts the question from the sensibility of insects to their intelligence - it would be wiser to leave their conduct unexplained, than to resort to an explanation which is no explanation at all, or which proves too much ; for many of the actions of bees and spiders, if they imply sight, imply also an intelligent and spontaneous use of it. But let us return to the consideration of the organ: one of its characteristics, which contradicts the analogy of all other eyes, is multiplicity. This may appear to some an insufficient reason for doubting the insect's power to see; for it is quite conceivable that the same sensorium which, in us and

- Spiders are not always so quicksighted as they have credit for being, nor do they always act as Reaumur represents them as doing. The following statement is not always borne out-"We have vibrated and moved the lines of a spider's web, so as to represent, as nearly as possible, the entrapment of a fly ; but we have, in no case, succeeded in bringing the spider to the spot, because his eyes have always detected our attempted imposition;" for I have, on the contrary, observed that when I held a fly buzzing, over and near a spider's net, she would sometimes peep at it, but not always; and I have frequently thrown bits of straw into the meshes of the net, and brought out the lurking Phalaris, who, having seized and turned the object over, with becoming indignation at this ill-timed amusement at his expense, retired in disappointment back again to his meshes. 
many other creatures, identifies and unites the two separate impressions of two eyes, might, in them, perform the same office with two hundred, or two thousand. Single vision with two eyes was explained, or formalized, by Dr Wells, as arising from the parallelism of the visual direction. Gassendi and Gall explained it by asserting, that only one eye at a time performed the function of sight. The more common and plausible view is, that the mind steps in to give its unity to the double impression, and to correct the fallacy of the sense. This power is said to be acquired by repeated use or habit, and therefore is only exercised when the conditions of the parts are the usual conditions ; but if the ball of either eye is disturbed by intentional pressure, or by disease, the double impression is not only conveyed to the mind, but remains a double impression, because, as the ordinary effect on the sense is disturbed, the ordinary operation of the mind is altered.* The

* In this statement, what is meant by the mind? Do we mean a judging or a reasoning power? Unconscious judgments, or unconscious reasonings, are desiderata in our manuals of logic, and, for the sake of science, it is to be hoped will remain such. But if this is not the meaning of mind, what is it? The only interference of mind conceivable in such a case, must proceed from that form according to which the sensitive faculty represents impressions-that is, from impressions converts them into objects. It is called a form, because the faculty itself is not to be considered as having recourse to it, or making use of it, so 
opular statement, that the eye and the hand correct each other, involves an absurdity; for before there

that we could say-here is the agent, and there the plan which it prescribes to itself to act in; for in this case it would be more properly called a formula, but it is the only possible mode in which this faculty can act. The senses are multifarious, and the impressions upon them coexist or succeed each other; but if $I$ receive the impressions from this or that sense, which sense first taught me to speak of these impressions as coexisting or succeeding each other, or of the space and time in which these two conditions are realized? This, it will be said, is intuitive; but it is a necessary pre-supposition to all sensual knowledge. Then it must be the necessary form of the faculty which, by uniting in one the data of the senses, makes them into knowledge. This faculty, as a receptive power, we may call sensibility; as an active power-i. $e$. as converting impressions into objects, by placing them in space and time-it has received the name of sensitivity. The word sensorium has been sometimes applied to the single point at which the mental principle communicates with matter. and sometimes to its material seat.*

Now, the sense of touch, although it may become the medium of representing objects in space, cannot convey the notion of continuous distance, which, when viewed as a conception, will be found to contain space and time in their undeveloped coexistence, or, as it may be called, indifference. But place, which consists in the representation of an object in space, irrespectively of time or space, limiting itself not according to succession, but absolutely, is the result of the exercise of the sensitive faculty on the visual impressions. There are, we say, two impressions-in what are they tuo? Not in space; for, as im. pressions, they are not in space at all, nor in any physical differences, for either organ, and the affections of either, are indifferent. The two impressions, therefore, differ in being two

- See Controversy between Clarke and Leibnitz. 
can be this right of search, and mutual exchange of delusions between the two senses, each, or at least one of the two, must know beforehand its own contents and limits, and, if so, will stand in no need of correction. But there is no incorrectness in saying, that the eye is enabled to enlarge the sphere of its exercise, by adopting the data of touch as auxiliary to its own. Let the reader now remember what has been said against the invertebrate tribes' having a brain, and he will see that, as there is no sensorium to collect, as it were, into a focus the multifarious notices of their so-called eyes, there can be no sight resulting from them; and that, as the organs exist,

-that is, in the scholastic phrase, they differ "solo numero;" but number is not yet a possible notion, for where there is no space, and the time is identical, how can there be number? Thus, under no category can the sensitive faculty apprehend these impressions as two ; for it, therefore, they are, or they become, one object. But an advocate for the reality of space will say, that the local source of either impression is different; and therefore, as the datum is twofold, and not merely the source of a twofold impression, the problem, why there is a single consciousness, remains unsolved. This very consideration ought to suffice for disproving the absolute reality of space; but at any rate we may reply, that as place consists in a certain relation of the object per se to the eye, the thing seen is in the same relation to both eyes. This is the parallelism of the visual direction, as stated by Dr Wells, but if the thing seen is in the same relation to both eyes, it is in the same place; and so, like a geometrical figure applied to another of precisely the same shape and magnitude, both pictures are one. 
they must have been bestowed for a different purpose. I may, however, here mention a curious speculation, which, though not requiring refutation after what has been already alleged, may yet interest some readers. A philosopher, of the highest distinction in our own country, has somewhere speculated on the possibility that creatures may exist, which, though incapable of appreciating the difference of colours as we do, may yet be so constituted as to receive the whole stock of their luminous impressions from a class of vibrations altogether beyond our limits. And true it is, that since perception of colour depends on the unequal absorption, or transmission, of the colourless compound of homogeneous rays which constitutes the solar beam, while the perception of form arises solely from diffraction-or, in other words, from modifications of light on the margins and angles of surfaces-the two perceptions are conceivably distinct. But I cannot see how the concessionmf such a faculty to insects will remove our difficulty. If an insect be supposed to have merely the perception of form without the perception of colour, the difficulties of the subject are increased ; and some of his actions, if they are sincerely believed to be his, and to be the result of vision, become still more perplexing. Guided by form alone, and unassisted by the coloured spots upon her wings, how shall the male butterfly know 
his Io from her rival Vanessa, as he chases her through the air? Or how shall the twilight-loving moth distinguish even forms, and avoid hurtful objects in his way? Surely the beetle, so circumstanced, "trepidabit arundinis umbram," would mistake every bulrush for an entomologist in disguise! The forms of flowers are frequently not dissimilar from other external objects; and extensive and precise indeed must be the perception of outline, which prevents that "winged confectioner," the bee, from making constant mistakes. Without the most exact "rapport des formes" in his head, the leaves of many a bush, or tree, would to him be undistinguishable from the petals he seeks. By what means should an eye, on which colour makes no impression, perceive white light, which is necessary to the perception of forms? How can we, or why should we, suppose the retina, which retains the undecomposed ray, incapable of being stimulated by chromatic light? When Puget saw the objects mentioned above through the adjusted eye of a flea, he surely saw his soldiers in their regimentals; his experiment did not put them all into the Austrian uniform. Then why not suppose the flea, in the exercise of his own eye, to enjoy a similar advantage? We may indeed be told, and told truly, that to know how a flea sees, we should not only see through its corneule, but 
from within its retina: still, I do not understand how this should apply to colour more than to form, which equally requires a retina; nor why a flea should recognise by sight any particular object, without all its visible properties affecting him. Some persons, it is known, distinguish colours imperfectly. Herschel, who examined the eye of an individual afflicted with this peculiarity, observes, that the defect arose from no insensibility of the retina to rays of any particular refrangibility, nor to any colouring matter in the humours of the eye preventing certain rays from reaching the retina, (as had been ingeniously supposed,) but from a defect in the sensorium, 'an incapacity of appreciating exactly those differences between rays on which true colour depends. The same incapacity, extending alike to form and to colour, in the entire absence of a sensorium, constitutes the insuperable objection to the belief of vision. If, however, the reader is not yet brought to the participation of my doubts, he cannot fail to be won over by the following sentences from Kirby, supposing always the statements in them to be correct. "The eyes of an insect are unlike those of other creatures who see, and are made on a different type. And their composition, according to Marcel de Serres and Cuvier, shows externally a cornea of various degrees of convexity, cut into facettes or corneules, 
whereof each is supposed to represent an eye. All these corneules are lined on their inner surface with an opaque varnish, and this varnish affords no passage for the transmission of light. Secondly, a number of short hexagonal prisms, entering the concavity of the lenses, come into contact with this varnish, and these it is usual to consider as so many retinæ, each having that relation to the particular lens with which it communicates. Next in order comes the choroid, which is penetrated by the prisms just mentioned, and which are given off from beneath it by the general expansion of the optic nerve, properly called the retina." How different are such eyes from our own ! The hard talc-like investment of the eyeballs is not less apparently than really callous ; for if you touch it with the point of a pin, the beetle does not even wince, nor does the irascible bee move a wing. Compare this unsentient, immobile, half-organized, dry, unprotected texture, with the exquisitely sensitive, mobile, moist apparatus of our own eyeball, (the conjunctiva and its appendages, ) and say if it be not rather a lantern than an eye. The eye, not only in man, but in all vertebrate animals, is the organ of expression; "nulla ex parte majora animi indicia cunctis animalibus," says Pliny, and the truth of this statement is amply borne out by observation. If we take our instances from amongst the higher animals, 
what a variety of character appears in the lion, the dog, and the gazelle; or if in birds, what softness in that of a pigeon! A hawk's eye is proverbial for its expression; nor are those in the duck or jackdaw less significant. Still lower, amongst reptiles, the malignity of the snake, by which he fascinates his prey, beams out at his eye; nay, even in the lowest of the vertebrated animals, fish, the hebetude of the organ corresponds with the hebetude of the creature ; but in insects the eye is utterly void of all signification. Nor is this always owing to the want of size ; for I find that the eyes of several Buprestidæ, of the larger dragon-flies, of water-beetles, and some grasshoppers, are larger, by actual measurement, than those of several small birds, beasts, and reptiles;-yet the smallest mouse has meek eyes, and the most tiny humming-bird has muscles by which to move his orbs in their sockets, and the very act is an expressive one ; while the smallest viper's eye has the full viper look in its glare. If insects' eyes look inexpressive, it is because they have nothing to express. There is, indeed, an ample allowance of retina-a retina for each facette, and a retina-retinarum, as it were, from whence each of them comes off; but if a black varnish be placed between the retina and the day, so as to intercept the rays of light, and to prevent them from penetrating to it, all this redundancy 
of optic nerve (as far as vision is concerned) can be of no avail. That light produces some effect upon the eyes of an insect, we may safely infer, from observing the conduct of an insect when subjected to this stimulus; but that it cannot act so as to produce vision, as Kirby conceives it to do, must, if his own premises are correct, be equally certain; for where no light can penetrate, no image can be traced. The retina, however exquisite its sensibility may be supposed to be, cannot see that which has not been painted on its surface. The insect being absolutely, and unavoidably, subject to the same external conditions for vision as ourselves, cannot be supposed to see through a black pigment, any more than we can through a white cataract; and as all insects equally have this black pigment, all must be equally blind.*

* I am aware that Müller considers this pigment to be the iris to each corneule which it subtends; and also, that he has seen, or thinks he has seen, a minute foramen, or speck, in its centre, to which (following up the supposed analogy between the eye in its most perfect form, and that organ as it occurs in insects) he has given the name of pupil; but, not to urge that this supposed discovery requires further corroboration before it can be admitted as an ascertained fact in physiology, the mere existence of a foramen, supposing it to be made out, does not prove that it is a pupil, nor that the black varnish in question is the analogon of the iris. The following consideration militates strongly with such a view:-The eye, in the enjoyment of sight, requires a perfect mobility of its iris-in other words, requires that the pupil should be in a condition to contract, or 


\section{CONCERNING SMELL.}

He who would assign to insects the full complement of the senses, will be in sufficient difficulty where to lodge some of them. In his "tam parvis atque tam nullis corporibus ubi tot sensus collocavit in culice? ubi visum in eo proetendit? ubi gustatum adplicavit? ubi adoratum inseruit?" As to the particular sense in question, it is agreed, among the books at least, that insects really possess it; and yet it is certain that none have hitherto been able to show the organ by which it is administered. Illustrations of the popular belief in this matter, however, abound. Insects in an apartment never fail, it is said, to detect and agglomerate round substances which gratify them, however carefully protected and kept out of sight. Now, as the discovery of a concealed object could not be accomplished by sight, (even supposing insects to be capable of seeing,) nor yet by taste before they have tasted, it follows that it remains only to attribute it to smell. The

dilate, according to the degree of light thrown upon it; a fixed pupil, and an iris impassive to the stimulus of light, occur only in amaurosis. The analogy, then, if there be any, between this foramen of unvarying dimensions, discovered by Müller, and our own pupil, exists only when the latter is in a condition which is incompatible with sight. 
stercoraceous beetle, and dipterous flies, which hover like vultures in the depths of air, are supposed to be attracted to the objects round which we see them swarm, by effluvia borne to their noses from the spot. In opposition, however, to this explanation, these insects sometimes arrive when the wind, from its opposed direction, would waft such effluvia away from them, or when the air, from its extraordinary stillness, is in a highly unfavourable state for the transmission of volatile matter from below. Induced by smell, however, as their biographer will have it, the larvæ of Dermestes loiter in old hides; Necrophori bury putrid moles, and other small animals, for future banquets ; and Staphylini and maggots collect upon the road-side carrion, as if in positive enjoyment of a stench which overpowers the passer-by. According to the authorities, indeed, insects not only affect strong and often nauseous smells; but it has been supposed to be by the exercise of this sense, that whole tribes are enabled to collect round the petals of flowers which to us are entirely scentless. There must be some fallacy in all this; and those who urge such inconclusive facts seem to forget, that, alive or dead, every thing in Nature, animal, vegetable, and even mineral, maintains its insect-parasite. The mushroom in decay allures the Beletophagus; the timber, which to us has no smell, maintains its 
Xylophagi and its Terediles. The frail Lithodomus, following his nose, if nose it be, through the obstacle of his own shell, bores his way into the rock.* The punctated Donaceas, the Necydalis of the red legs, the sulphur-coloured Cistela, the Hoplice with azure scales, and the Quaker-coloured sisterhood, the Lepturce, are all supposed to find in corollas, whose colours are to us their only attraction, an agreeable stimulus to their first pair of nerves! And why, it may be said, should not an insect's smell surpass our own? Does not the dog; with his "Odora canum vis," excel his master? Are not the eyes, and perhaps the nostril too, of the predatory birds, superhuman, beyond all comparison? The general objection, however, still obtains here which has been repeatedly urged elsewhere-the absence of a brain to receive the message of the sense, and to determine the consequent act. Besides, before we presume the superior perfection of the sense, it seems reasonable to demand evidence of the superiority of the organ. The sportsman's dog, and the carnivorous bird, have these in conformity with their superior faculty. In the first instance, there is the large humid nostril, with its corresponding display of nervous matter: and in the second, a very copious development of the optic nerve. But if we hesitate to admit, or

* "Deducit scopulos, et montes rumpit aceto."-Juvenal. 
deny, the sense of smell to insects, in what other way can we explain, or how indeed can we explain at all, such facts as have been intimated above? Indeed we know not! but this we certainly know, that there are many acts performed by insects which cannot be explained at all by the operation of any of the senses, nor by all of them together; acts which we are fain to refer, accordingly, to the mysterious power called instinct. It would, therefore; be taking less for granted, and would perhaps be more philosophical, to refer at once to that endowment such of the above acts as have been gratuitously referred to the sense of smell ; inasmuch as it is more simple to extend the domain of an admitted principle of action, of which, though its nature may be a mystery, we must recognise the existence, than first to claim an organ which we cannot demonstrate, and then confer on it altogether extraordinary powers. Some writers go the length of supposing an insect accessible to volatile emanations through his stigmata, or pores; by the help of which vast olfactory apparatus-since it is coexistent with the whole length of his bodyhe might, no doubt, have perceptions of smell that we cannot reach. Huber's experiments, instituted to prove that bees can smell, and also to determine the precise organ of this sense, prove too much, and even contradict each other. He placed honey in four 
small boxes, differing from each other in shape and colour, and made to open and close by card-shutters, placed over apertures on the lids. These boxes being placed at 200 paces from an apiary, were in a short time covered with bees, who from the outside soon discovered the openings, through which, but for the valves, they might have access to the honey; and when they had found them, penetrated into the boxes. Extreme delicacy of smelling is here, he thinks, undeniable; since the honey was absolutely out of sight, and even its effluvia were confined. The same author, having dipped a pencil in oil of turpentine, (the smell of which is said to be very offensive to insects generally,) carried it gradually near the head, antennæ, and the eyes of bees, without the least effect; when, however, he brought the illsmelling preparation near the cavity of the mouth, above the insertion of the proboscis, the insect instantly started back, beating his wings in great agitation, and would have taken flight had not the offending odour been withdrawn. The bee becoming presently pacified, the ingenious tormentor again brought the pencil to the same part, and with exactly the same symptoms of aversion, only that the bee, in this instance, took to fanning itself with its wings, as if the sooner to disperse the detestable emanation. How can he do otherwise than 
conclude that the organ of smell in a bee lodges either within the mouth, or in some part contiguous to it? Yet if the sense of smell in the bee is so fine as the first experiment would represent it, how is it that his nose required to be actually touched with turpentine before he was warned off in the second? There can be no doubt, from these experiments, that certain odoriferous substances do not produce effects upon the irritability of insects, unless they are brought into immediate contact with their mouths : thus the identical Huber, having filled the mouths of bees with paste, found that he could then present to them either petroleum or turpentine without exciting any moyement; some of the bees climbed about the apparatus, and even walked over the poisoned brushes, as if they had been free from all disagreeable smell; but this does not prove the mouth to be an inlet to the nerves of smell. Odoriferous substances are also volatile, and owe their odour to this circumstance :if, then, the volatile particles are prevented from coming in contact with that organ, the irritability of which should respond to them, the part would not be stimulated, and none of the acts consequent upon its stimulation could occur. These experiments, while they show that the insect's body is not, as some have supposed, every where accessible to volatile particles of matter, certainly neither prove that 
insects smell at all, nor that the organ is situated in the mouth.

\section{TASTE.}

LET insects feel, hear, and smell, or not, without any apparent organ for doing either-mouths they certainly have, and therefore, it is presumable; taste. "Without taste," says an eminent modern writer, " no animal could continue its existence; it is a sense indispensable to all organized beings, though its peculiarities cannot always be traced to the structure or form of the organs." This statement, however, is an assuming of the question, nor is it possible to acquiesce in it. Do not the absorbents select without tasting, and are not some animals little else but absorbents?* That some insects show a marked preference for this or the other kind of nourishment is, if true, any thing but conclusive as to their taste; for one is at a loss to conceive how, if insects were led by flavour to the choice of food, so many should be found to feed on insipid substances. Are we really to believe with some authors, that it is in tender consideration of a future progeny that the Hypoderma bovis places her ova only upon the backs

* John Hunter has not inaptly described the absorbent system as " the animal of many mouths." 
of young cattle, aware that her progeny would find it harder to penetrate an old hide, and fare worse if they succeeded? Is any one seriously disposed to maintain that his own blood is a source of animal enjoyment to a flea? "Bees," says Darwin, "are aware of such sorts of honey as would injure themselves, and will not therefore taste any of these." Now, though it may not perhaps impugn the bees' taste, it does seriously impair his character for design, (unless, indeed, he intends to poison us,) that, with the choice of so many flowers, any of his family should ever have chosen ill, and have made such honey at all. It is said to be in virtue of this sense of taste, that thirsty butterflies, weary of dancing in the air, descend at intervals to earth, to drink all in a row, like horses at a trough-and it is also said that ants are rather hard drinkers : indeed, a narrative of Huber's makes it impossible to doubt that they are insatiable as to water. The feet of an artificial formicary were plunged into vessels filled with water, meant to prevent the escape of the ants; but the contrivance proved a source of enjoyment to them in their captivity, by supplying them with a plentiful beverage during the heat of summer. "One day, while they were assembled at the moat of their prison, and busily licking up the little drops that filtered between the fibres of the wood-a mode 
of watering which they preferred to taking it fresh from the basin-I amused myself," says our author, "in chasing them away; butsucceeded so imperfectly, that a certain number only could be made to retreat at all. One, who had been driven off by force, came shortly back, and approaching a friend of his who had stayed, and was apparently absorbed in the pleasure of drinking, poked him with his mandibles, and assaulted him over and over again, before he could succeed in driving him off. He then went on the same errand to another, whom he more readily persuaded of the propriety of moderation in all things, after which friendly offices he retired to the society of the bell glass." The supposition of design in all this, implies something more than mind; some cultivation of morals also seems necessary. An intemperate subject of a republic renowned for its moderation and frugality, is only saved from the consequences of excess, by the fortune of having for his friend a wise and egregious citizen. To make the romance better, it is pretended that it is in consequence of those acrid, or acid, fluids of their economy, which redden litmus paper, and become the property of the chemist, that ants are necessarily thirsty. Then why did the drinking-club consist comparatively of so few?

May not ants require water, as plants require 
water, for the general purposes of their economy, without being subject to the inconvenience of an appetite, which would make them liable to the torment of scarcity, or, when too abundant, call upon them for the exercise of discretion?

\section{HEARING.}

Most naturalists agree in attributing hearing to insects, while all confess ignorance of its organ -for as such antennæ cannot be recognised; since in all the variety of forms which they present, whether moniliform, clavate, jointed, comb-like, and so forth, we look in vain either for the hollow of the hearing trumpet, or for the conch-the shape the most suitable to the collection of sound; nor can a member be supposed to be designed for its transmission, which has, like many of the antennæ, a joint, or knuckle, at the middle, by which one half of the passage is at an angle to the other. Moreover, in many cases, antennæ are inserted, not into the side of the head, but near the end of an elongated snout, as in the Curculiones; sometimes they lie buried in a deep gutter, as in many of the Buprestidoe, and they are frequently longest and largest in those creatures which, being dumb, should also 
be deaf. Nor do antennæ exist in any form in the spider; those, therefore, who affirm that he hears perfectly without them, have already concluded that they are not ears. Most insects, as far as we can judge, are silent; still the sounds produced by the noisy ones, as they cannot be supposed to be addressed to our ear, but to those of their own kind, form part of the evidence adduced in favour of their possessing the sense of hearing. Among the noisy community are bees, wasps, hornets, flies, cicadæ, musquittoes, crickets, and grasshoppers. The beetle tribe also affords several well-known contributors, as the Anobium, the Dorcadion, the Lamia, and some other Longicoms; the Lepidoptera, or butterfly tribes, supply the death's-head moth, which squeaks like a mouse, only more piteously. Some of these insects are not only noisy, but are remarkable for the kind of sounds they produce;-more so, indeed, than for any thing else. The silent division includes the prudent ant, the wily spider, (far be it from me to speak of them without their epithets,) and the Staphylinus, celebrated justly for her maternal tenderness. The infinitely various sounds of the first class of insects, of some of which we are daily witnesses, have also been declared by competent authorities to have their meaning, and if not to be exactly rated as articulate sounds, are at least supposed to consti- 
tute an instrument of useful communication to the

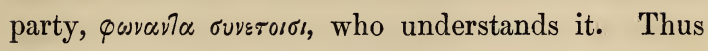
at is believed-or at least this has been written-that the whirring sounds produced by the vibration of crisp wings, the friction of limbs against the elytra, the jarring of tense membranes, \&c. \&c., are not to be regarded as the idle exercise of insect mechanism, like the ticking of a watch, but as intimations of purpose, or even of passion. Listen ! say the Entomologists, and you will no longer doubt. As soon as one cicada springs his rattle, a neighbour from the green cover overhead answers to the call; and in a few seconds the chorus becomes general, and the whole wood is all strophe and antistrophe. Of noise, indeed, the cicada makes enough ; and though poets embellish it by various choice epithets, it must be owned that there are ears to which it only recalls the nasal monologue of Punch, or the performance of a penny-trumpet. The melancholy click of the "Death-watch" (Anobium) loses all its terrors, when it is found that this ominous sound is not a voice, but the mere result of mechanical friction. You have only to send him a counter-scratch from your side of the wainscot, when, mistaking you for a brother Anobium, he returns the signal. Entomologists declare that they have been able to train Anobia to do this trick at 
pleasure, by first accomplishing themselves in the accurate mimicry of the sound; meanwhile attend, say they, to that poor fly's note of despair as he finds himself suddenly in the net, and in the presence of his arch-enemy the spider! Mark how the cricket drops his crick as you approach him! And how the silence spreads before and around you as you tread over a newly-mown field of grass, which was, a second before, and will soon be again, enough to stun you with the noise of grasshoppers ! If it be objected that others are altogether noiseless, down come the philosophers to ask, "Who knows what inappreciable ghosts of sound may not flit in social intercourse between creatures so diminutive?" But is it plausible that such a silly insect as a fly shall be able to buzz his satisfaction (for thus they interpret his bourdonnement)' when he has nothing else to do, and that insects far more intelligent than he should have been left destitute of such a convenient thing as voice? No; it is to meet this objection that Wollaston andHerschel have attempted-though, as I think, unsuccessfully - to make out the possibility, in all instances, of insects communicating with each other by means of sound. "There is nothing," says Herschel, "in the constitution of the atmosphere to prevent vibrations much more frequent than any of which we are conscious, and therefore, 
animals like the cricket, whose powers appear to commence where ours terminate, may have the faculty of hearing sounds which at present we do not even know to exist; and there may be other insects which, though they hear nothing in common with us, may be endowed with a power of exciting, and a sense of perceiving, vibrations of the same nature as those which constitute our ordinary sounds, but so remote, that the animals who perceive them may be said to possess another sense, agreeing with our own solely in the medium by which it is excited, and possibly wholly unaffected by the slower vibrations of which we are sensible." If we adopt this supposition, the insect sounds we hear may form but a scantling of their language, and it will be only the high-pitched notes of fellowship or of contention that reach us. This speculation, however, while it removes all difficulty in admitting that insects may take counsel together, and we be none the wiser, places the insect higher in the scale of creation than this distinguished philosopher can have intended. They must be few who will not demur to the probability, that such a gift has been given to the minute and often impalpable insect as has been denied to the half-reasoning elephant, and to that problem in natural history, the dog. What are the grounds for supposing that the sounds of which our ears are 
conscious mean any thing at all? or that a cricket expresses fear when he suddenly ceases to utter them,supposing him for a moment capable of that emotion, and omitting to enquire of what he was afraid? or, if "instinctive fear" be spoken of, if fear be made a result of instinct without experience, this really is nothing short of a contradiction in terms. Instinct is opposed to fear; for instinct is, on all hands, allowed to be something which supplies the place of intellect; while fear is an active state of the intellect itself. There can be no fear where there is no ground for it; and there can be no ground for it unless the intelligence finds one. If some creatures like the cricket suspend their note at our approach, how many others, who had acted more wisely in doing so, buzz about our persons in the very act of tormenting us, and incur all the consequences. The musquitto, if he had sense enough to be afraid, would surely not so loudly and pertinaciously proclaim his intention of attacking us, nor, by so doing, reveal his whereabouts.

Whilst all entomologists assume that insects in general possess the sense of hearing, they yet admit of exceptions ; for some assert that bees do not hear. White trumpeted to them loud enough to hail a ship at a mile's distance, and declared that they took no heed whatever; and this indifference of bees to 
sound has been confirmed by others. There is, however, no doubt that they follow cymbals, which may disturb the air more than wind-instruments"quaque movent sonitus ara sequentur apes.* Unlike the cricket, bees make more noise the nearer you go to them; because, say certain writers with whom such phrases are not rare, "They have an instinctive dread, mingled with anger, at your intrusion." Whether they carry on their communications by means of sounds, which we can or cannot hear, may be doubtful ; but that, for the purposes of fellowship, they confer together, is maintained by Huber, who seems to have asked himself with Wordsworth-

"What other spirit can it be that prompts The gilded summer-flies to mix and weave Their sports together in the solar beam, Or in the gloom of twilight hum their joy?"

The variety in the forms of the antennæ, which has been already noticed, and from which it has been adduced that they cannot be ears, is not only great, but is based upon such substantial differences as to prove that they cannot be the organs of any one sense in particular; and although it would, no doubt, be much more satisfactory if we could at once and with certainty point out the real use of the 
antennæ, instead of showing what functions they do not perform, still their manifold and very marked differences, and their want of resemblance to any of the organs of sense, as stated above, are circumstances which cannot be set aside; neither can we, in our wish to find an explanation of their use, create for them a new office by supposing a new sense: the five senses are not fictions, which they would be, if we could suppose any other communication between mind and matter than those of which they are the medium. It is not maintained here that the qualities of the outward world have an existence independent of the senses; but unless we would relapse into that sceptical idealism which has been long exploded, sensuous impressions must be founded upon something real; though what is the nature of their reality, and the mode of their connection with the real, remains still a matter of controversy. Hence, it is impossible to conceive any unknown sense as a substitute for the others, nor any sense at all besides those which man, in whom the sum of all the gifts of nature centres, is conscious of possessing. The readiness with which some authors have done violence to this natural conviction, is, in the main part, owing to that apparent intercommunication between certain insects, which seemed to them to imply intelligence. As they knew that wherever there was 
intelligence there must be also sensibility, they found less difficulty in contradicting experience and analogy, in the question of sensibility, than in resisting a conclusion which daily observation seemed to force upon them; they were more ready to affirm the existence of a sense when all the conditions and most of the organs were wanting, than to ascribe seemingly intelligent acts to accident or to a blind principle. Perhaps a little closer attention to all that was involved in either alternative would have produced a different result; but certainly every allowance should be made for any one who, being possessed with a deep conviction that insects partake of understanding, does not even think it worth his while to attend to circumstances which might cast a doubt upon the subject. If what has now been written against the probability of insects possessing the senses be correct, it will follow that their actions, whatever may be their efficient cause, cannot proceed from "sensuous impressions;" a circumstance to which the reader's attention is particularly called, because many authors, although disposed to think with Huber, that as nature had not given intelligence to these creatures, they cannot have the means of taking counsel together, of exercising forethought or forecaution, nor of learning any thing, (although their conduct is such as to lead to a con- 
trary supposition,) yet imagine that in all cases the stimulus to every act which they are obliged to perform is the gratification of some particular sense. "When bees," says Huber, "construct cells, educate the young grubs, or collect provisions, we must not consider that they act by plan, affection, or foresight; but that the enjoyment of some pleasurable feeling, inseparably annexed to the performance of each act, is the real efficient, and the determining motive of each." Now, let us for a moment suppose all that has hitherto been written against insect sensibility to be unfounded, and that, instead of being without feeling, insects are highly sensitive; if this be supposed, and if we grant to them the highest amount of sensation, by this alone their conduct cannot be interpreted. An act is often accomplished before the motive of pain to be avoided, or pleasure to be gained, comes into the field. For instance, though there were pleasure in the act of union between bee and bee, butterfly and butterfly, this (as they cannot be aware of it beforehand) does not explain why sex should seek sex; or, if the construction of that waxen prism (the bee's cell) should in some mysterious manner gratify his sense of touch more than the forming of a square or of a triangle of the same material, the question still recursWhence comes the bee, who cannot sensually enjoy 
the form of her cells while they are only in contem-plation, to set about their construction? What organ of sense can be gratified in undertaking the moral duties of education? and is the pleasure of tasting them shown in eating or in storing up sweets? It is obvious that mere sensuous impressions cannot determine the conduct of any insect; there must be also another and a higher element in a perception of the end proposed, as well as a knowledge of the means of attaining it. So great, however, are the wonders told by credible witnesses and excellent men of the intercommunication of bees and ants, that, like a surprising vision which for a time takes away from the seer the power of challenging or studying what he sees, they at first overcome the mind, and completely abash the spirit of enquiry. It is scarcely worth while to call in question the accuracy of this or that narrative as they occur in the various works upon insects; for, even though the credibility of one or two should be shaken, more than enough would remain to demand a different and a much more difficult solution. To repeat many of these stories, inasmuch as they can easily be found elsewhere, would be useless; but a few of the most striking, together with one or two cases for which I can personally vouch, may perhaps not be uninteresting to the reader. 
Huber maintains the intercommunication of bees, and is convinced that the antennæ are the means by which it is brought about. Without disturbing the operations of its inmates, he divided a hive into two parts, by interposing a grating which was too close to permit the passage of the insects from one compartment to the other. The bees contained in that division of the hive which did not contain the queen, soon exhibited marks of unusual commotion: but having become satisfied of the fact that they had lost their sovereign, they set about rearing new chambers for the accommodation of a new ruler. How had the bees found out that they were in the wrong box? Had the others told them of it? Had they seen it? Or did the sense of smell inform them of the unfortunate position of their queen? The holes in this apparatus had not been made big enough to let the antennæ pass ; another experiment was therefore contrived so as to make the contact of these supposed organs possible, and the result was such that Huber, who had a preconception how the matter should be accounted for, was soon satisfied of the truth of his suspicions. A queen was placed under solitary confinement in a cell made of glass, to one side of which was fastened a grating large enough to allow the passage of the antennæ, but too small even for the heads of the bees to follow them. The perturbation which 
had before followed the loss of the queen did not take place now. All was quiet; for it seems the bees knew that she was not lost, and when she was set at liberty they seemed at once to recognise her. This experiment differed from the other only in the opportunity afforded for the protrusion of the antennæ, which in fact were seen poking about, as the author undertakes to say, for information. The conscious object of these enquiries, as soon as she discovered the interest they took in her, acknowledged it by remaining stationary on the grating, and by crossing antennæ with such of her loyal subjects as she delighted to honour. The antennæ appear to be quite an insignificant feature in this history. The bees, in the first place, got their information in the former experiment without them; but one would fain know how it can be explained that these bees, however instructed of the loss of their queen, should begin to make other cells for the rearing of a new one, and should promise themselves that their future queen would be in a capacity to lay eggs, (for this was the end of their exertions, and therefore the motive also, if they acted intelligently,) and yet that another group of these intelligent creatures should not perceive that the queen, in the second experiment, was just as unable to lay eggs in which they could have any interest, unless set at liberty, as if 
she had been barren; in which case it is known well they would have given her up, and turned their attention entirely towards a new election. Here they do no such thing, and seem aware that, in fact, it is merely an experiment of curiosity !

The following instance of the same faculty in ants is sufficiently surprising for a romance, but stands upon record as an authentic history. A pot of molasses stood in a place infested by ants; the owner, tired of driving them off ' pro re nata', performed one grand act of expulsion on the intruders, and slung the pot up to the ceiling of the room: a single ant, however, escaped his vigilance, and stuck not in, but to, the treacle, from which, after taking as much as he thought good for him, he went his way. To accomplish a retreat there was but one road; ants do not fly; it was necessary for him to crawl up the cord, take to the ceiling, and descend the walls to join his comrades, all of which measures he duly and diligently executed. Shortly after his safe arrival, the whole body of ants was seen leaving its quarters, marching upon the treacle-depot by the selfsame course, and descending the same rope-ladder into the "happy valley" in which their friend had rioted -no jostling was there; no impeding each other's progress:- the fasting went down in one column, the full came up in another, and the vessel was soon 
licked clean. The above story comes from no less authority than Franklin, as an irrefragable proof of insect intercommunication.

The Pinnaphylax is a small crab, naked like Bernard the Hermit, but is furnished with good eyes, and lives in the same shell with the Pinna. When they want food, the Pinna opens its shell and sends its faithful ally to forage; but if the Cancer sees the Polypus, he returns immediately to the arms of his blind hostess, who by closing the shell avoids the fury of the enemy. When, on the other hand, the forager has procured a booty, he brings it to the opening of the shell, when it is admitted, and they divide the prey.

In an Italian forest I once came upon a piece of footpath, covered for several feet with swarms of ants, evidently occupied in something in which they had a common interest, and it turned out to be war. A detachment of the "Formica ruficollis," which wore a dark uniform with a red collar, was coming forth from the grass in which their encampment lay; they made for a large chestnut-tree, upon which a considerable number of black ants, (Formica pubescens,) insects of three times their stature, were posted, and taking measures to receive them. There appeared to be so much ferocity, and so much purpose, in the manœuvres on both sides, that it was im- 
possible not to be interested while looking on. Having stopped some time to observe them, I saw several of the besieged party, as soon as any one of them took a prisoner, carrying him up in his mouth to a Tarpeian height, and then let him drop on the plain below. The red-necked ants, on the other hand, in immense force completely surrounded the enemy's position, and stood ready with their jaws open to seize any straggler from above, who was sure to meet with no quarter when the fortune of war had placed him in their power. Many of the episodes in this heroic poem were curious enough; and among the most so were those produced by my interfering, and amusing myself by backing the reluctant, and placing obstacles in the way of the enterprising. Here, while the fact of intercommunication seems strong as possible, its supposed import makes it take a very high character, for-

"Communi dare signa tubæ, defendere iisdem Turribus, atque una portarum clavi teneri," are privileges which have been hitherto held to be peculiar to man.

I once observed a settlement of small black ants (Formica picea) occupied in carrying supplies along the most frequented path of a garden. As, in looking out of window at the proceedings of a mob, one cannot fail to notice any individuals who distinguish 
themselves, I had occasion, being favourably placed, to notice the proceedings of two ants in particular, charged, jointly, with a load too large for their strength. This industrious couple, in meeting others who (as is their well-known habit) would have been proud to join them, went out of their way to avoid receiving assistance, which, to all appearance, would have been very seasonable-foolish ants! But they soon recovered their character for sagacity. Arrived near the entrance of their warehouse, they deposited the object which had cost so much labour, and went forward to reconnoitre the dimensions of the hole which was to receive it. After looking down for some time, and seeing that it would do, they fetched the burden to the edge of the pit, went down, and dragged it after them-sagacious ants ! They must have agreed to assure themselves of the size in the first instance.

One day, later in the season, a body of the same ants was gathered together under a parsley-plant four feet high, of which the slender stalk was heavily charged with seed; the seed was falling fast, and, as it fell, they rolled it off to a place of security with most obvious regularity, and every appearance of attention. But the operation was much more curious than it at first appeared; - the seeds did not fall spontaneously; they were gathered by a party sta- 
tioned on the branches of the plant, who stripped it as men gather apples. One ant was working away for nearly half a minute before his mandibles had succeeded in getting an individual seed sufficiently loosened to drop it to his colleagues below; at least twenty others were similarly occupied; and, as the seeds fell, away they went. One seed alone, in a particular instance, remaining attached to its stalk, the ant that took it off, as if perceiving that there was no more labour to transact on the spot, in place of throwing it down to his companions as before, kept possession of it, and made his way with it to the ground.

Allian has related just such a story, in which grains of wheat are substituted for parsley-seeds ; these grains were dropped by the gatherers above to the populace below.

A friend, on whose perfect accuracy I can rely, gives his experience of the sagacity of ants in the following interesting recital :-In a villa near Geneva his bedroom was overrun with ants. After looking about to find from whence they came, he one day discovered that a rod of iron, which was in immediate communication with the garden under his window, was the means by which they gained access to his dormitory. From this, therefore, he repeatedly shook them for some days, killing a great many, until at last not 
one was any longer to be seen on the iron rod as heretofore: still they infested the premises. One night, happening to go to the balcony to look at the moon, which was at its full and shining very brightly, he was struck by a sparkling appearance on the iron rod, and on examining it he found it covered by niyriads of ants. Alarmed at the death of so many of their tribe, and warned by those who had escaped, they must, he thinks, have taken counsel together, and, knowing the hour at which he was not likely to be in the way to molest them, have agreed to change their early habits, and burglariously to enter the premises after dark.

It will be said that none of these acts can be attributed to instinct, for this power executes uniformly and blindly the same perpetual task; whereas here the conduct of the individual is adapted to circumstances. If so, he acts with understanding, for it is the characteristic of that faculty that it deals with what is contingent, and regulates the selection of means according to emergencies. Some persons speak of insect-intelligence in a way which leads me to suspect that they mean something more by the word than the understanding, as insects manifest it ; they cling to it as a formula for charming away certain difficulties which beset the question. But if insects are intelligent, they must possess that intel- 
ligence which the higher animals also possess; for there is but one understanding as there is but one sensibility, and the operations of the one, like that of the senses which minister to the other, are defined and limited by the same rules in all cases. The data may be different; the vividness of the faculty may be unequal; but its starting-point, its ways and means, and the results, will be the same in every class which partakes of it. Now, when the dog occasionally startles us by his conduct, which seems to bear the stamp of reason, why do we resist the conclusion which circumstances seem to force upon us? Is it because we do not think a few instances sufficient? No :-it is not only on the principle of refusing inadequate evidence, and because we wish to guard against accident or delusion, that the smallness of the number of the examples is objected to, but because the faculty itself is such, that nothing short of a continual manifestation of it will satisfy us of its existence: and as we say, that if a dog had reason it would display itself in moral and intellectual works, and not in solitary glimpses afforded now and then, so we may say, first, of insects in general, that if, as such, they are endowed with understanding, we have a right to expect it in all; and secondly, that if bees, ants, or spiders, are so endowed, it is incumbent on them to show it consistently, and in every kind of 
subject-matter. No other class in nature displays in itself the extremes of cleverness and stupidity. One bird differs from another, and one beast from another, in the degree of his intelligence ; but that in one and the same organization, (that of insects,) there should be creatures without a certain faculty and others with it, is an absurdity which no one will entertain. Do they all, then, display understanding? Does the male butterfly do so, who, attracted by his female, (though she be stuck through the body on to a collector's hat,) comes, as it were, on purpose to be taken, and meets accordingly with a similar fate? Does the Lucciola show understanding, when he cannot distinguish the flaming wick of a candle to which he hurries, from the light which his mistress hangs out for the very purpose, it is said, of alluring him? But take the insects upon whose actions chiefly this notion of insect-intelligence rests, and here let the reader accept a sequel to the anecdote, the last but one related. By way of cross-questioning the sagacity of these ants, a quantity of the desirable seed was deposited half-way between the plant and the anthill. By availing themselves of it, they would have saved half the journey and half their labour; in place, however, of doing so, and seizing the advantage, they passed by $y_{*}$ and actually walked over every grain of it, and persisted in picking for themselves 
from the distant plant! On many occasions besides the above, a generous endeavour has been made to assist the labour of insects, but always fruitlessly ; the ungrateful creatures have sulkily pursued their course, in place of profiting by any suggestions which, if acted upon, would have lessened the duration of their work. A remarkable case of stupid inaction; where escape, had intelligence existed in the insect, might have been effected, is afforded by spiders. Often I have pinched off with tweezers from the Aranea domestica, sitting in her toils, one of her limbs, and after shaking her lines for some seconds, she has stayed to lose another, and been quite dismembered before it has occurred to her to climb, by one of her countless threads, to the ceiling, and get out of harm's way.

I will next detail the unexpected behaviour of a spider and certain flies, which were introduced to each others' acquaintance. The Dryops italicus was confined with a fly (Musca carnaria) in a glass box : the fly no sooner got near his enemy than he flew, as if fascinated, into his grasp. The spider seized him "more majorum," and in a few seconds slew him : four ants of the kind called Nigra were then put in, and with them another fly; the ants, who had been deprived of several of their limbs, were dropped in right over the spider, who was still busy with his first victim. The instant he saw the 
ants, in place of either courting their acquaintance or dividing his attention between the fly and them, he got away with his booty between his mandibles, while the ants followed in place of avoiding him! The glass prison being too slippery for earrying a load, he dropped his fly and easily got out of the way. The fly had scarcely fallen from the mouth of the spider when it was seized by the ants, all crippled as they were, who turned him over and over again, and proceeded to carry him off as a desirable prize. At this moment, the spider being perfectly at leisure, another fly was introduced, who took up a position within an inch of the tyrant, and began to plume himself as if in perfect security. The spider saw the fly, but still retreated. The fly now flew into the spider's face, the latter seeming the most frightened of the two! Finding no way out of the box, after moving about from side to side, the fly made as if he would join the party of ants, still occupied on the carcass of his own kind; on becoming aware, however, of their occupation, he retreated, and began to rub the sides of his head, as one observes those insects frequently to do; after which gesticulation, he planted himself like a setter on his forelegs, and remained stationary while the ants passed by with the dead body. The flies (the living and the dead one) were now withdrawn, and the spider was presented with three new ants, one of 
which immediately ventured on an act of aggression, by catching hold of him by some part near his mouth. The wounded spider dragged himself on with some difficulty, and when the ant left him he was found to have received a death-wound, inflicted in less time than he had formerly taken to kill the fly.

Surely there is much in the last recital which is contrary to expectation, and unaccountable; a spider kills one fly, and yet avoids another of the same size and species. Whatever impulse made him kill the first, should have made him attack the second also. If it were hunger that prompted him to destroy one, it had not yet been appeased, for he was only beginning to enjoy himself when he was presented with the second; so that the conduct of the spider is alike inexplicable on the supposition of hunger or of ferocity. The dread which flies have of spiders is supposed to be strong; yet here was a fly acting as if conscious of the impotence of the spider to take advantage of him! In opposition to this seemingly exquisite discernment in the fly, was the egregiously absurd behaviour of the mutilated ants, who seized on the first booty they could get, although they had no access to their magazine in which to store it. If there be one instinct stronger than another, it is that of these insect-camels to carry burdens!

If insect intercommunication were really a series of intelligent acts, what useful experience might not 
flies impart to each other, and so save the lives of many thousands of their fellow-creatures, and make us, to whom they give so much annoyance, far more comfortable? A little violence committed on a handful or two, in a room full of these troublesome visitors, and the judicious sacrifice of a few legs and wings, would effectually deter the many who had not a mind to be maimed; but a fly never takes warning! One of these insects will hover on the margin of a saucer of milk, in which his friends are drowning all around, and almost touching him, and he will continue to sip away on the edge of the precipice, or even spring boldly into the ocean below.

It is easy to collect from such facts, and they abound, that the same insect which in some instances shows more than human intelligence, commits just as often the most remarkable oversight. Neither a mouse nor a hen will ever be tempted into the water; but the locust, notwithstanding the superior sagacity which he is said to exercise when mischief is to be done, though unable to fly far under the best circumstances, and obliged to light at brief intervals for rest, will, nevertheless, undertake a voyage of half a league, which he cannot accomplish, and so rush on inevitable destruction. "In the months of May and June, I have observed," says Haselquist, " the arrival of these insects in myriads from the 
south, directing their course towards the nor. thern shore; they darken the sky like a thick cloud, but scarcely have they quitted the land when the surface of the water is covered with their dead bodies." In like manner ants, on reaching the bank of a river, in place of having the sense to stop, and at least take counsel together and enquire for the bridge, will rush madly on, and are instantly carried down by the stream. Many insects, as is well known, will fall to the ground when any ore approaches the shrub to which they had retired; cuddling up their legs, they will fall into a trap, or even into your hand, and, as the Entomologists say, will "pretend to be dead" to defeat your purpose; but as it frequently happens that the insects which choose this expedient are winged, and so might have recourse to a better, we must either deny all intention to this act, or censure it as in the highest degree a foolish one. Caterpillars, when about to become butterflies, are found to have by no means advanced in intelligence. If a side-slit is made in the cocoon which involves the pupæ of the great peacock-moth, (who is on the verge of emerging into butterfly existence,) he will rather persist in making useless efforts against the impenetrable and obdurate end, than turn round and avail himself of the open one. Yet Entomologists assert that the silkworm perfectly knows what 
she is about, when, having finished the cocoon, she fixes her head opposite to the unglued apex by which the perfect insect is to emerge, and never places the point against any object which might prevent the moth from emerging. A certain beetle called the pill-beetle, who rolls his posterity along in a bolus, or ball of dung; to a suitable depot, was once known, when the said ball had fallen in a wrong place, to summon three able-bodied assistants to the spot, to help him out with it! Intelligence could hardly go further : but try him on another scent, and you will give up your protégé as a blockhead; for he adopts, at once, any false ball that you may treacherously substitute for his own. This experiment may be easily tried during the summer time, when large detachments of these beetles may be frequently seen, each rolling on with his hind-legs a ball containing his egg-if you deprive him of it, and then substitute another, he will not detect the cheat, but will adopt the changeling, and roll it on, nothing doubting, as he had before rolled on the other. A creature who, failing in his endeavours to execute a task, has sufficient intelligence to solicit aid, ought not to be so regardless of what he has himself manufactured, or to be so little aware of the genuine quality of the interesting materials he had put together, as to take up any round object in its room ! The carrion-fly 
is said, now and then, to lay her eggs on a certain flower, the smell of which resembles putrid meat, which is the object of her desire. Her posterity must on such occasions perish, owing to their parents' stupidity. The Brachinus pops off a series of discharges, which, in place of alarming you, as he is supposed to intend to do, make you only the more inclined for the capture of so curious a creature. A sad blunder is committed by the earth-worm, in the very action to which some writers assign a considerable share of wisdom. Whenever the noise of scratching is made in the vicinity of his lares, believing that it is his formidable enemy the mole boring his way at him, he comes forth for security;- -he has, however, made a mistake;-the stranger at his door is the lapwing, who, acquainted with the weakness of his mind, and his particular fear of moles, scratches in his neighbourhood to bring him out, and gobbles him up as soon as he comes. In examining an insect-net after it has swept the grass for capture, any one may observe that the ant, who, on the showing of his historian Huber, is next to man the most intelligent of creatures, seems least disposed to improve the opportunity to escape from his reticulated prison. The bee bounces off resentfully, the grasshopper springs in a bound of unusual vigour, every other insect makes the best use of its legs and wings to be off, 
but the sagacious ant lingers behind! A strong blade of grass, the leg of a beetle, any thing worthless that he can possibly lay hold of, is sufficient to detain him: yet he blockades his door every night at curfew, and at cockcrowing removes the wooden bars, except on rainy days, when the doors of all anthills very properly remain sealed. On one occasion I could not help contrasting the industry, skill, and memory, as it would of course be called, of one individual of the formica family, with the preposterous proceedings of some of his friends. A wise and laborious ant was toiling up the bark of a chestnut-tree, and pulling after him an entire snail-shell, the size of a hazel-nut. He halted occasionally, as well he might, but he never lost hold of the shell, though the mere weight of it, one should have thought, would have pulled his mandibles out of joint. In a few minutes he had raised it upwards of three feet, and all was going on prosperously, when it so chanced that three or four idlers of the ant kind, and presently as many more, met him on his way. Our labourer had almost done his work; his hind-legs were already within the hole into which it was his plain purpose to introduce the shell, when the new-comers, (who, as we have seen, are always ready to help one another,) proceeded to do just the reverse! They got upon the shell, they entered it, they persisted in 
sticking to it: he could not carry it; and then the shell swerved to one side or the other, according to the disposal of his friends within, who had not even the sense to trim the boat; still, by great exertion, he held fast, and might perhaps have accomplished his task, when two more strangers thought proper to contribute their weight, and brought on the catastrophe. The weary but persevering insect was obliged to "let go," and the shell, freighted with three "insides" and half a dozen "outs," fell to the ground! They left the conveyance in apparent alarm, and scampered off in all directions, while he remained for some time fixed to the spot of his discomfiture. The shell being subsequently examined, was found exactly to fit the hole in the direction in which the ant was dragging it, and in no other. Here we have one wise ant, but nearly half a dozen idiots; nor is it the only instance in which the conduct of this insect has appeared in one relation sagacious, and in another defective in common sense. I lately noticed the carcass of a large dead bee, moving as it were by some unseen mechanism below. On a nearer examination, I found the bee to be supported on the shoulders of half a score of the smallest ants, (Formica flava,) who were dragging it along like a huge unlaunched ship, at the rate of three feet per minute. So intent were the 
ants on their work, that they were not to be seduced from it by the allurements of moist sugar and other dainties sprinkled over their path. Nothing could exceed the skill with which they overcame every obstacle that presented itself; they would sometimes straighten the joint of one of the bee's legs, or raise the margin of his wing, or even turn him completely over. After working in this way for half a day, they brought him to the door of their house, which was in the wall of ours, where, the entrance not being big enough to admit him, I left them late in the evening, fixing him up in a corner for future operations. The following morning I found him lying dismembered, apart from the ant-hill. Now, if these ants had reflected, would they not have pulled him to pieces where they first found him, and so have saved themselves much unnecessary trouble?

If we cannot impute to insects an understanding, it is also pretty certain that they cannot have our passions. Yet this absurdity has been virtually maintained by many writers; whilst others, seeing where such an admission would lead them, have had recourse to a most infelicitous phrase, which being in itself a riddle, and meaning nothing, I content myself with simply recording. Not being prepared to allow human emotions to insects, these writers attribute all their acts to the mysterious working of 
a power which they designate as an "emotional impulse!" Many will not dispute with you as to the degree of intelligence possessed by a bee, a hornet, or a gadfly; but few have any scruple in representing them as indulging in anger or revenge. According to some, insects never forget an injury! Common parlance shows this persuasion to exist. A proverb warns you that "a trodden worm will turn upon you" in resentment, and certain tempers derive a current epithet from the ill-conditioned wasp!. At certain seasons, however, stingingnettles are more prone to sting than at others, and it might as fairly be said that they did so vindictively, as that the Æstrus or Hippoboscus torment horses or cows with an intent to do so. Many flies sting only before rain; yet we do not in such cases admit malice, any more than when the Lytta or Medusa blister our fingers, or when a flea sucks our blood. Why should we suppose there is more illnature in a hornet, a gadfly, or a gnat, than in those parasite tormentors, the Acarus, the Pediculus, or the Morpio? Is it from the hardihood with which they first come forward on wing to meet us? or that the loudness of their noise, while they assail or wound us, sounds like a bugle of defiance? Aristotle relates that a certain person who assisted the inhabitants of a bee-hive in driving away the swarm 
with which they were at feud, was evidently recognised by the assisted party as their ally and benefactor. Bees are grateful!

Two queen-bees, when they are at a "dead-lock," and perceive themselves in such a predicament, that in giving a death-wound they would receive one, think it time to separate, deeming " discretion the better part of valour," but having exhibited in the first instance undeniable evidence of proneness to revenge. "At my father's house," writes M. Desormes, in his interesting treatise on bees, "a horse once got loose, and entering the garden, overturned two bee-hives. The bees immediately settled upon him, occupying especially the most tender parts of his body. In the evening he was found lying dead, and covered with bees, who were sticking to him, and continuing to sting the dead body; nor could we succeed in driving them off-so great was their fury-until we set fire to some straw, and threw it over the carcass." The same author also relates that a swarm of bees, which he had detached from a bough to which they were clinging, crept up under his shirt sleeve, (he had no coat on him at the time,) and settled on his arm. In this position he carried them for some distance to the house of a friend; when, his shirt-sleeve being slit open, he 
detached them all from his skin, without receiving one sting, by holding his arm over a current of smoke. The bees, aware of his harbouring no illwill towards them, were not to be outdone in consideration. In the Levant, indeed in warm climates generally, bees are said to be much more irascible than in temperate latitudes, the same fact being asserted of scorpions, spiders, and the scolopendron ; the interpretation of which fact, in all probability is, that heat, while it renders these creatures more active, renders the poisonous secretion more acrid, and perhaps more abundant. "In Syria," says Della Rocca, "it is unsafe to pass before a bee-hive unless under the protection of smoke; while in some parts of Germany bee-hives are kept in open courtyards, and no one is ever assailed by their inmates." Are we to impute one moral character to the bee of Syria, and another to the bee of Germany, rather than attribute the difference between them to climate, acting on the principle suggested above? The female glow-worm is said to be very amorous in her propensities; and some Entomologists affirm, that she not only gives light to attract the male to her bower, but that she exercises a voluntary power over it, so as to dispense it more or less vividly, according to the strength of her passion. It would 
be difficult to establish the truth of the first assertion, and impossible to ascertain that of the second.*

To those who have been taught to use the word reason as the exponent of all that distinguishes man from beast, the following remarks of Kirby will not be a little astounding:-_" There is no surer criterion of reason, than after having unsuccessfully tried one mode of accomplishing a purpose, the devising a new one to the same end; and that insects are able to stand this test, is to be shown in many of their transactions." A large slug, allured by the hope of plunder, had crept into a bee-hive, and was stung to death by the bees; he was too unwieldy to draw out of the hive, they did not think him good to eat, and, left as he was, they knew he would breed a pestilence. In this embarrassment they did what was next best, they had recourse to their own propolis; they gummed over the dead body of the slug,

* It is probable that this insect, as well as the kindred Lucciola, (in which I have ascertained the fact by experiment,) dispenses two sorts of light-one of a fluctuating character, sent forth in jets corresponding to the number of its inspirations, which is quenched instantly on removing the head; the other, a constant steady light, which abides for days after its death. This latter light, when nearly extinguished, may be revived by plunging the insect into warm water; and a French writer pretends, that if it be brought into contact with hydrogen, an explosion will take place. 
and he was made into a mummy, not as an object of value, but because he had become an object of alarm! Bees, then, are aware that decomposition will follow death, that hurtful emanations will follow decomposition, and that there is such a thing as malaria! Pretty well for bees! And they were wrong after all; for the hive would not have suffered from the decomposition of the slug. To suppose them capable of providing against future inconveniences, or to allow them any idea of the future at all, would seem concession enough ; but to suppose them prospective of ill health, in the shape of fever or any other specific disease, and applying an effective varnish to restrain it, is a specimen of that idolatry of facts, and recklessness of principles, which has been the increasing characteristic of our age.

A sagacious contrivance of the bee in windy weather, seems first to have been mentioned by Aristotle, who tells us that in high winds they carry a small pebble for ballast, a relation too striking not to have been adapted by Pliny. "Si co-oriatur procella apprehendi ponduscula lapilli se librant." This relation, though doubted or denied by some recent writers, and amongst others by the author of "Insect Miscellanies," seems to rest on good evidence. Della Rocea, who (Huber excepted) knew more about bees than any body, assures us that those 
who affirm the ancients to be wrong, have confounded the mason-bee, who carries his mortar, with the labouring-bee, who carries nothing about him but wax, adding, that if the objectors had attended accurately to what they saw, they might also have perceived, that while the mason-bee bore the raw material for the construction of his house in his mouth, the hive-bees carried their ballast in their arms." * Does the bee, then, know what he is about? Has he become aware that the wind will have less power over him if he steadies himself by a weight? There is no ground here for pretending that he acts as his sensations prompt him, because no sensations of any kind can suggest such conduct, except by the intervention of thought; and a rational act, though it may be attended with sensation, can only be explained as a work of reason. If such an act be, in any sense, his own, he must be aware of the universal proposition, that wind has less influence on a heavy than on a light body; nor is this enough-for as he adopts the experiment as soon as he can fly, as soon indeed as he is in existence, he must have the thing in his mind before he can have tried it. Whence got he this knowledge? Reason deals with practical concerns according to experience. Experience, which

* Delita Rocca. Hist. Complète des Abeilles. Tom. iii. p. 137. 
is reason acting on observation, derives one of its constituents from the senses; but as in the case of the bee there can be no experience, all explanation is hopeless if we conceive the action to originate with the bee himself. The like observation applies to the following recital of Huber's, where the accommodation of this insect's instinct to occasion is yet more remarkable:- " Having placed a slip of glass in front of a comb which some bees were constructing, they seemed immediately aware that it would be very difficult to attach it to so slippery a surface; instead, therefore, of continuing the comb in a straight line, they bent it at a right angle, so as to carry it beyond the obstacle, and ultimately fixed it to an adjoining part of the woodwork of the hive, which the glass did not cover. The direction, if the comb had been a mere simple and uniform mass of wax, would have evinced no small ingenuity; but it is to be borne in mind that a comb consists on each side of cells, having between them bottoms in common. If you take a comb, and, having softened the wax by heat, endeavour to bend it in any part at a right angle, you will then comprehend the difficulties which our little architects had to encounter. The resources of their instinct, however, were adequate to the emergency. They made the cells on the convex side of the bent part of the 
comb much larger, and those on the concave side much smaller than usual; but as both the large and the small cells had as usual a common bottom, they were no longer regular; but the small ones were considerably larger at the bottom than at the top, and conversely with the larger ones." Again, it is stated by Huber, that some hives of bees having been frequently attacked by the death's-head moth, and robbed of the best part of their honey, at length so effectually closed the entrance with arcades, walls, casements, and bastions, built with a mixture of wax and propolis, that the insidious marauders could no longer intrude themselves. A wasp was observed in the act of carrying off a fly of nearly his own size : in order to be able to rise with him, he first took off his head, but the wings, still attached to his body, being found to offer too great a resistance to the air, he descended again into the garden, where, to the wonder of Dr Darwin, (which I sincerely partake,) he neatly bit off the wings, one after the other, and then bore him up without difficulty. I subjoin Edwards' interpretation of the behaviour of this wasp in a series of acts, which are all deposed to by competent witnesses-" Quelque chose agit sur les ailes de cette mouche, et m'empêche d'avancer; si je veux regagner rapidement ma demeure, il faut que je m'en débarrasse, et pour cela 
le meilleur moyen c'est de retourner à terre et de les couper." " Nothing short of reasoning," adds $\mathrm{Mr}$ Edwards, "will account for this series of actions." A German artist, a man of strict veracity, and for whom the license accorded by Horace to painters as well as poets needed not to be invoked, stated to Mr Kirby the following circumstances, of which he was an eyewitness. "I observed a species of Scarabœus busily engaged in making a pellet of dung, in which, according to custom, to place his posterity; this, when he finished, he pulled to the summit of a small hillock, and then let it roll down, for the purpose, it seemed, of giving it cohesion, and improving its rotundity by the agglomeration of earth which each time adhered to it. The ball, during the process, fell into a hole, out of which all his efforts to extricate it were vain. After ineffectual attempts, he repaired to an adjoining heap of dung, and soon returned with three other beetles, who applied their united strength to raise the pellet, and at length succeeded in heaving it out: which being accomplished, the auxiliaries left the spot and returned to their quarters." The instinct of these beetles, however, is not always to assist each other, but sometimes the reverse, as is proved by the following recital, of the accuracy of which I take the responsibility upon myself. The "dramatis personæ" are 
two beetles, whereof one was most troublesome in disturbing the designs of the other, who sought to bury a dung-ball containing his family; now rolling it here, now there, and stopping occasionally to see if the earth was soft enough for the intended excavation. Whenever she stopped, the other came up and eontested the possession of the ball. The subsequent proceedings of those two beetles were so interesting as to rivet my attention for some time; nor could any one, who had seen what was going on, have failed to believe that the beetles were actuated by motives; and had actually calculated the steps by which to attain their end. Thus, no sooner had the one excavated a sort of tunnel of some inches in length, and conveyed the ball into it, there to be safe from the repeated attacks of the marauding beetle who so pertinaciously beset his path, than that "artful dodger," hiding himself behind the earth that had been thrown out, began to bore in the direction of the other's intrenchment. Whether he afterwards lost his head underground, or whether some unforeseen obstacle opposed his progress, is uncertain; but I observed him, about ten minutes afterwards, emerging with a load of earth upon his back, just in front of the cave where the other beetle was at work, who forthwith rushed out to meet him, and drove him back. A pause of a few seconds suc- 
ceeded this discomfiture of the offending beetle, who then wheeled round, made a circuit of two or three yards, climbed the bank, halted immediately over the subterranean passage of his rival, and striking the ground from behind, like a dog when he begins to dig, would soon have made a considerable hole but for the obstacle of a pebble, which I poked out of his way with my stick. No sooner was this done, than he set to work again with incredible vigour, and in a very short time had sunk a shaft directly into the other beetle's hiding-place, which he entered at once. Both beetles were now lost to sight for about a minute; then they issued together from the mouth of the tunnel, and after fighting for some time, one opened his elytra and flew off, and the other returned to his work. Not to suppose design in all these various acts seems difficult; but on the other hand, to impute to pill-beetles all the intelligence required for civil-engineering, is impossible.

"La fourmi, tous les ans traversant les guérets, Grassit ses magasins des trésors de Cérès ;

Et dès que l'Aquilon, ramenant la froidure, Vient de ses noirs frimas attrister la Nature, Cet animal, tapi dans son obscurité, Jouit l'hiver des biens conquis durant l'été;

Mais on ne la voit point d'une humeur inconstante, Paresseuse au printemps, en hiver diligente."

It is chiefly the foresight of the ant which poets, 
at the instigation of naturalists, never fail to celebrate. Whenever sloth is to be reprehended, or frugality commended, the "Magni formica laboris" appears on the scene;-but, alas for the correctness of statements with which our ears are too familiar! This creature, which fabulists and moralists, from Solomon downwards, have been so fond of extolling, and recommending to our imitation, must now, it seems, be censured by the veracious historian, as both a laborious idler and a miserable hoarder for hoarding's sake; for it is ascertained that ants never open their mouths to eat or to drink the whole winter through-so that they collect without an object, and accumulate what they cannot enjoy. It is your philosopher that has been imputing to ants, from the beginning of time, designs of which they never dream! The ant-hill or supposed magazine of provisions, turns out to be a deposit of quite another kind, as we are assured by a respectable author in his memoirs on these interesting creatures. Not that their works on that account lose one iota of the character of design, but the end proposed is different:the grains thought to be provision, are merely rubble, or loose building materials. "Ce ne sont point des provisions de bouche; ce sont de simples materiaux qu'elles font entrer dans la construction de leur édi- 
fice, comme elles y font entrer des brins de paille," \&c. \&c.

The solicitude of ants for their young, and the care they take in transporting them from place to place, has not been overstated. The working ants know, it is said, the precise degree of heat which their health requires, and never fail to bring the young ones to the surface when the warmth of the atmosphere is propitious, or to bury them deeper according to the progress of the cold. As soon as these larvæ are hatched, the parent ant begins to bring in the debris of dead bodies found by the way, or sometimes drags a struggling worm into the fatal shambles, when it is divided, and accurately apportioned to each in equal rations: the elder members of the community never touching food till the younger ones have been fed, and are satisfied. When one of the labourers is accidentally wounded at his work, he is assisted by the others, and taken to the hospital; but if his case be evidently past the skill of surgery, his body is thrown away among the rubbish of the nest. For a particular instance of the sagacity of ants, the following may be related:- " A wall had been erected with the view of sustaining a vaulted ceiling, still incomplete: the ants who had begun constructing it, had given it too little elevation to meet the 
opposite partition, upon which it was to rest. Had it been continued on the original plan, it must infallibly have met the wall at about one-half of its height, and this it was necessary to avoid. This state of things very forcibly claimed my attention, when one of the ants arriving at the place, and visiting the works, seemed to be struck by the difficulty which presented itself, and immediately obviated it by taking down the ceiling, and raising the wall on which it had reposed; it then, in my presence, constructed a new ceiling with the fragments of the former one." *

When a spider catches a fly, if he be small she kills him at once; if he be too large to attack openly, she envelopes him in her net; but if he be so large as to risk injuring the net, and his escape is inevitable, she detaches the cords by which he is held, and helps him to get away. Nor is the fly less sagacious on his part:-on more than one occasion I have seen these insects walk over a dead spider, whose mortal enmity they had no longer any cause to dread.

The Cassidæ, a tribe of insects frequently of gaudy and beautiful colours, are so aware, it seems, of their own charms in Entomological or other unfriendly eyes, that they adopt the same expedient, which was devised by the great French wit for a 
similar purpose, and smear their bodies with dung ; * or, failing to procure it, they plant themselves under the spikes of thistles, which enables them to escape notice, or to parry the attacks of predatory birds.

It is pretended that the Dytiscus, or plunging water beetle, in his half-witted larva state, makes himself soft and clammy, hoping that he may effectually escape by being disagreeable to handle. The Crysomela with the same view, is said to eject, when handled, fotid liquids, and the Meloe also; but unsuccessfully, since his acrid qualities have enlisted him in the service of medicine.

The CEstrus equi places her eggs, not on any part of the horse indifferently, but on such parts only as he is accustomed to lick-knowing that if deposited without that circumspection, great part of her posterity which is to be hatched within his body would perish.

Evelyn gives the following account of the intelligence of a Roman spider, which, espying a fly at three or four yards' distance upon the balcony where he stood, would not make directly to him, but " crawled under the rail, till, being arrived at his antipodes, it would steal up, seldom missing its aim; but if it chanced to want any thing of being perfectly opposite, it would at first peep, and imme-

* " Je m'envelope en ordure pour rendre ma personne inviolable," says Rabelais. 
diately slide down again, till, taking better notice, it would come the next time exactly upon the fly's back; but if this happened not to be within a competent leap, then would this insect move so softly as the very shadow of the gnomon seemed not to be more imperceptible, unless the fly moved, and then would the spider move also in the same proportion, keeping that just time with her motion as if the same soul animated both these little bodies; and whether it went forwards, backwards, or to either side, without at all turning her body, like a well-managed horse; but if the capricious fly took wing, and pitched upon another place behind her huntress, then would the spider whirl its body so nimbly about as nothing could be imagined more swift, by which means she always kept her head towards her prey, though, to appearance, as immovable as though it had been a nail driven into the wood, till by that indiscernible progress, having arrived within the sphere of her reach, she made a fatal leap, swift as lightning, upon the fly, catching him in the poll, where she never quitted hold till her belly was full, and then carried the remainder home." Nor is the intelligence, if he have any, of the Silpha vespillo, a burier of dead bodies, behind that of the Congener beetles, recently mentioned. His ordinary instinct is to make a hole, more than a foot below the surface 
of the soil, under the carcass he has found, till he has buried it-to effect which may require a month's labour. If he cannot do it all himself, he flies off for aid, and returns with a number of friends, who help him to accomplish his work. If they find the ground impracticable for boring, they carry the dead mouse, or mole, further on till they come to a softer soil. Even this is nothing to what Gleditsch relates of the talent of this insect. "I planted a bent branch in the ground; to the crooked end a string was attached, and to the string a dead mole. The string was only just long enough to permit the mole's body to touch the ground. Some Silphce, allured by the smell, tarried not to come; and getting, as is their habit, under the small carcass which I had prepared for them, began to scoop out the earth; but the descent of the body not keeping pace with their excavations under it, came soon to hang over the hole they were preparing for its reception. This was noticed by the miners; who came out, looked about them, took counsel, and after a long deliberation, finally marched up to the gibbet, undermined it, and in a short time brought the whole down within reach of their endeavours :-

“Qu'on m'aille soutenir après un tel récit

Que les bêtes n'ont point d'esprit!

Pour moi, si j'en étais le maître, Je leur en donnerais aussi bien qu'aux enfans." 
De Geer relates that the female Pentatoma griseum (a common field bug) protects her young brood, who follow her as chickens do a hen, against all intruders, their own father included, who always destroys them when he can. On one occasion, he happened to walk close to a covey of these little beings, when the mother began to beat her wings, and continued to do so until he had drawn back several paces.

Among Lepetopterous insects, the Tinea pillonetta, or cloth moth, deserves to be celebrated on account of its interesting proceedings. "Like us," says Bonnet, "Tinea are born naked; but, unlike us, as soon as they are born they begin to think of clothing themselves. They do not dress in the same uniform, nor employ the same materials in the fabrication of their garments; there is, indeed, a greater difference in the art of clothing amongst them than among the different nations of mankind." The particular Tinea in question, which is a little cylindrical worm, makes itself a little muff of exactly the same shape as its body, and open at either end. The stuff is manufactured by the insect itself; and consists of silk of its own furnishing, and the detritus of the eloth on which it feeds, and out of which it makes its dress. When its covering is completed, it lines the interior, in immediate contact with its 
skin, with very soft silk; it never puts on a new dress, but, as it grows, goes on adding to the old one. This is easily lengthened by adding some of the same material at each end; but to make the coat fit when the body grows broader, is a more complex affair : this it does by slitting open the cylinder half-way down, first on one side and then on the other, and connecting the parts thus let out by very ingeniously adding new pieces, which are sutured on to the old by means of silk, of which the little creature keeps a constant supply. If a Tinea which has fed on red cloth for a time, be put upon a blue one, the sutures will be blue, and he will appear in a short time in a party-coloured harlequin dress.

But there are some proceedings of insects, which, if their own, would require not merely knowledge, but foreknowledge, and which, if properly acts and deeds of theirs, must make them, what I think scarcely any one will pretend them to be, possessed of superhuman power. Let us hear Paley.

"There is another kind of oviparous economy which is less likely to be the effect of education than it is even in birds ; viz. that of moths and butterflies, which deposit their eggs on the precise substancethat for example of cabbage-from which not they, (the butterflies,) but the caterpillars which are to 
issue from their eggs, draw their appropriate food. The butterfly cannot taste the cabbage, it is no food for her ; yet in the cabbage, not by chance, but studiously and electively, she lays her eggs. Amongst other kinds there are the willow-caterpillar and the cabbage-caterpillar; but we never find on the willow the caterpillar which eats the cabbage, nor the converse. This choice, as it appears to me, cannot in the butterfly proceed from instruction-she had no teacher in her caterpillar state. She never knew her parent. I do not see, therefore, how knowledge acquired by experience, if it even were such, could be transmitted from one generation to another. There is no opportunity for either instruction or imitation; the parent race is gone before the new brood is hatched; and if it be original reasoning in the butterfly, it is profound reasoning indeed. She must remember the caterpillar state, its tastes and habits, of which memory she shows no signs whatever; she must conclude from analogy, for her recollection could not serve her, that the little round body which drops from her abdomen will at a future period produce a living creature, not like herself, but like the caterpillar, which she remembers herself to have been. Under the influence of these reflections, she goes about to make provision for an order of things which she considers will at some time or 
other take place; and it is to be observed that not a few out of many, but that all butterflies argue thus-all draw the same conclusion." Notwithstanding which conclusive argument, it is currently affirmed by some, that spiders are prescient of changes about to take place in the weather, when they spin a shorter or longer web, according as the glass is to point to " changeable" or to " set fair." Authors of repute affirm that bees know beforehand when their queen is about to declare herself, and testify this foreknowledge by buzzing about the still closed door of her vestibule. Bees are also said to foreknow that there will be a deficiency of thyme long before it flowers, and therefore to kill off many of the boarders to prevent the community from starving. The actions of the Ichneumon strobillella might well be quoted in proof of foresight-if any proof could support such an extravagant supposition. Just as the progeny of the moth, long since deposited between the segments of the fir-cone, are beginning to become caterpillars on their own account, this ichneumon comes to make preparation for her future family, and to destroy theirs : for, "instead of taking an unoccupied abode, which should seem more convenient, she may be seen buzzing about and thrusting her tail between the apertures which are not big enough to admit her whole body, till, 
coming at last upon the depot of young caterpillars, she there, by selection, plants her pernicious eggs, which, being hatched, destroy every one of them. Observe, the fly in question has no self-interest in what is done; she requires at her own frugal meal only a little honey-her act is strictly prospective. She knows that her unborn progeny will require living insects!" *

From the above examples, which it would be alike foreign to my purpose, and useless, to multiply, it appears that the intelligence which prompts the actions of the dog, or of the higher animals generally, has no share in bringing about any of those of which insects are the agents:-First, because, as we have seen, anterior to all experience or apprenticeship, they execute faultlessly whatever they have to do. Secondly, because on the supposition of the conduct of an insect proceeding from intelligence at all, we should be obliged to admit that he shows in one part of his conduct a greater, and in another a less, amount of it, than could possibly proceed from one and the same individual; and lastly, because many of the daily actions of the insects cannot be explained by referring them merely to intelligence, but suppose prescience as well, which, as it is not an attribute

* Wilkin. 
of brutes, can much less be supposed to belong to creatures so vastly below them as insects.

One more fact corroborative of an essential difference between instinct and understanding may be here noticed; viz. that in animals of the highest class, where the evidence of intelligence is most conspicuous, that of instinct becomes faint in proportion. The duck, on the authority of $\mathrm{Mr}$ Kirby, is only known to perform seven or eight purely instinctive acts; while the self-reasoning elephant, his superior in mental endowments, executes fewer still. Whereas in the bee, who is wholly "without understanding," the same author enumerates thirty distinct acts of instinct, and adds that this number might be easily doubled. Nor is the "ants' republic" less well endowed in this particular than the "realm of bees." The rule indeed seems of universal application, that the more the instinct the less will be found the intelligence, and conversely. If instinet be thus clearly distinct from intelligence, it is certain that intelligence is not less distinct from reason; this last being independent of, and anterior to the other.* Bacon was well aware that the distinction between the two was not a distinction merely of degree, but of

* The characteristic distinctions between reason and the understanding are well pointed out by Mr Coleridge in his "Aids to Reflection," p. 227. 
kind. "I do not approve," says this illustrious writer, "of that confused and promiscuous method in which philosophers are accustomed to treat of pneumatology, as if the human soul ranked above the soul of brutes merely as the sun above the stars, or like gold above other metals." 


\section{DIALOGUE.}

" 'Tis wonderful,

That an invisible instinct should frame them

To royalty unlearn'd ; honour untaught;

Civility not seen from other; valour,

That wildly grows in them, but yields a crop

As if it had been sow'd." -

Cymbeline.

Friend.-I am so far convinced by your arguments, as to own that I cannot refute what you have said respecting the improbability of insects having sensibility: indeed I am, on that subject, more than half your proselyte. You have convinced me that insects do not reason even when they seem to act reasonably. You have also shown me what instinct cannot be ; but you have not given me any thing positive by which to replace the vague persuasion which you have obliged me to relinquish.

Author.-In my mind, instinct is but another manifestation of life itself ; an act, whether it be vital or whether it be instinctive, is referable to one and the 
same vital principle, the seat of which is not, in either case, to be looked for in the brain.

Friend.-I can hardly persuade myself that the power by which such wonders are accomplished can be identical with that by which the heart beats, and the functions of the glandular system are executed. I am, however, far from requiring any explicit statement on a matter of so much mystery, and am rather inclined to agree with Bonnet, that, in order to understand it, one should be able to take up one's position in the head of an insect, and at the same time preserve one's own individuality.

Author.-As an insect has no brain, and therefore has not an intelligent head, that part of its body, even if you were within it, would furnish you with no better point of view than any other. Instinct, though a sovereign that will be obeyed, has no throne; but, like life, pervades every part which moves: hence, I consider instinctive and vital acts to be but different manifestations of life, executed in accordance with the pre-established harmony between the creature and the external world. No word of philosophical origin has become so familiar as instinct; and yet, whenever a definition of it is attempted, how marvellous is the want of precision as to the thing signified! Such vague language as the following could hardly have been expected from 
the first naturalist of France. "We can no otherwise conceive what instinct is," writes Cuvier, "than by admitting that the creatures which exercise it have, in their sensoriums, certain innate and abiding images, or sensations, by which they are urged to act, as we are by ordinary and accidental ones: a kind of dream or vision haunts and impels them; and in all that relates to instinct, they may be considered a sort of somnambulists." Who, after a moment's reflection, can entertain such a speculation? A spider possessed with such a fixed, predominant, somnambulatory idea of net-making, ought never to leave off weaving them; and a bee who has made one cell, should spend its whole life in rearing similar constructions. Besides, in the case of the dreamer or the somnambulist, several functions of mind are supposed; but I take it for granted you have renounced all claim to mind on the part of an insect. Nor is any thing learned from Adélon and his sect, who call reason a cerebral act exercised by a voluntary power, and instinct a cerebral act which the creature does not will to execute, but which it cannot resist.

Friend.-This certainly appears very much like saying that instinct is synonymous with madness; for what is reason without the control of will to guide it, but madness? 
Author.-True; and the believers in this doctrine, though they would hesitate to avow it, must in fact regard insects, if not as dreamers or somnambulists, as so many tiny maniacs.

Friend.-What do you say to Lamarck's account of instinct, who defines it "the power by which simple ideas are formed, without the further capacity in its possessor of combining them to form complex ones ?"

Author-I should say that the insect who was really capable of forming any simple idea, could also form a complex one; since the process by which an idea of any kind is formed, must always be the same ; and I should add that something beyond simple and elementary ideas were required for almost every act which an insect has to perform.

Friend.-Some authors, though content in ordinary cases to call the actions of insects instinctive; seem to think, in extraordinary ones, (those, for instance, in which the ordinary instinctive act is varied to meet a corresponding variation in external circumstances,) that the interference of some other power is called for; and, proceeding upon this idea, $\mathrm{Mr}$ Coleridge designates such acts as acts of " instinctive intelligence."

Author.-I think this term an unhappy one.

"With perfect instinct, that unerring guide, What Pope or council shall they need beside?" 
Instinct is, or is not intelligent. If it is, then the expression is tautological-only another way of saying " intelligent intelligence;" if it is not, it is an attempt to qualify that which is intelligent by something which has nothing to do with intelligence.

Friend.-You say that instinct has nothing to do with intelligence; you will, however, admit it often displays results which closely resemble those of understanding?

Author.-No one can doubt it; but even if the lower faculty, instinct, (the seat of which is irritability,) had advanced into a higher faculty, sensibility, (the seat of which is the nervous system,) it would not even then have reached the still higher faculty of intelligence.

Friend.-And therefore, in using the term "instinctive intelligence," $\mathrm{Mr}$ Coleridge probably

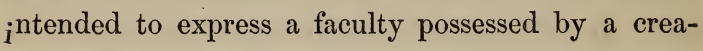
ture endowed with sensibility, which should stand midway between instinct and intelligence.

Author.-To this I offer no further objection than that insects have no sensibility.

Friend.-Well, I am convinced that instinct cannot be identified with intelligence; and so far you have shown me what instinct cannot be. But by what process do you arrive at the conclusion that the seat of life and of instinct is the same; and that in 
fact there is a close correspondence and analogy between them?

Author.-By simply divesting instinct of accessories with which it may or may not be combined, and by which, when it is, its character is masked; by considering it alone, as I contend it must really exist in animals which have no brain. In the higher animals, sensibility and intelligence coexist with instinct : in the lower animals, instinct and life stand alone. To make what follows about instinct plainer, I will first say a few words on the nature of life. A living agent, which cannot be identified with that reason which in man is conscious of its ends, nor with intelligence, which in the $\mathrm{dog}$ is selective of its means, nor yet with the operations of sensibility, (which is the ground of appetite,) so as to originate in itself the spring of its movements-is not reduced by this exhaustion to the state of a merely passive thing, of which all the movements are owing to external causes. Let us, on the other hand, suppose a power which differs from the attraction of bodies, and the affinity of chemical substances, in being always localized, or, more properly speaking, centralized, so that its beginning can be determined, (whereas the affinity or the attraction is not more in $\mathrm{A}$ towards $\mathrm{B}$, than in $\mathrm{B}$ towards $\mathrm{A}$ - that is, does not reside in the substance at all, but is a law 
exterior to them :) such a power, though in its operations it must be conceived of as starting from itself, and as being therefore of a higher order than the elective tendency of inorganic bodies, still need not rank so high as simple desire, much less as intelligent choice :-such a power, lower than intelligence, lower even than sensibility, but higher than any law of exterior nature, ${ }^{*}$ we comprehend and refer to under the epithet of vital, or acknowledge without a definition when we speak of life. It is the first true individuality, and is to inorganic nature what subjective light or seeing is to objective light, or mere visibility. The inseparable attribute of this vital power is to act. The particular action depends on the irritability, while the capacity to act at all comes of its own nature. Neither is the energy of which we speak a mere impatience of inaction, but an impulse tending to a definite end or purpose; and if the form which prescribes the kind and manner of the vital act did not pre-exist, the outward prompting or stimulus could produce no effect upon the agent. If we attend to the operations of some of the higher

* Higher, by the same rule which assigns a higher rank to sensation than to growth, or to memory than to sensation, or to self-consciousness than to memory, because each is a stage nearer to true unity; a deeper penetration towards the unapproachable Centre of all Being. 
plants, we may notice in particular organs the manifestations of this power, which, when it is displayed by the whole creature, we call instinct.

Friend.-Will you mention a few instances to exemplify this?

Author.-Certainly. (1.) The radicles of plants extend themselves in the direction of moist earth, in preference to dry; the final cause being the support of the plant, which else had perished for want of supplies; but the efficient cause is to be sought in the adaptive power of the radicles themselves, which select this direction. This power to select in plants has indeed been doubted, and it has been explained as merely the result of a " tendency to increase in the direction of the least resistance, which tendency would, it is alleged, be sufficient to direct the root to the moist situation."

Friend.-But does a moist soil always offer the least resistance? Is not a dry marl, for instance, less tenacious than when it is moistened? And would so strong a force as vegetable growth (a force which dislocates mortar and destroys the strongest masonry)* be influenced by such differences as the comparative tenacity of soils?

* “_-Saxis cinerum custodibus ad quæ

Discutienda valens sterilis mala robora ficus."-JuvenaL. 
Author.-I do not think it would; at all events, any mechanical explanation of the direction taken by the roots of trees is rendered null by the experiments of Knight. He enclosed certain seeds in the middle of glass tubes filled with mould; of which the portion above the seeds was moistened, and that below them was dry. This arrangement, however, made no difference in the usual mode of growth; the radicle penetrated downwards into the dry earth, the plumule took its course in the opposite direction : "guided," as Darwin elsewhere says, " by a vegetable irritability similar to that of the lacteals and the lungs," the one penetrated into the earth for its pabulum, while the other took its accustomed direction upwards.

"Instinct with life, the buried seed now shoots On earth's cold bosom its descending roots; With pith elastic arms its rising stem, Parts its twin lobes; expands the throbbing gem. Soon in bright veins the silvery sap ascends, And refluent blood in milky eddies bends ; Till, spread in air, the leaves respiring play, And drink the golden quintessence of day."

(2.) The absorbents of plants exercise a selective power in what they take up: a fact that many able physiologists have attempted also to account for on mechanical principles; and certain examples at first sight seem to countenance such a notion. Thus, if 
plants be immersed in different kinds of solutions, they absorb most rapidly from the thinnest, and out of the solutions of greater density, it is the watery particles which are principally taken up; as is shown by the increased specific gravity of the mixture when the plant is removed. This, therefore, proves that the size of the nutritive particles is adapted to the calibre of the absorbent; but it proves nothing beyond this; while the fact that plants will take up some neutral salts, and reject others, (however fluid. the solution which holds them may have been,) shows selection.

Friend.-Is it not true that if opium, belladonna, or metallic salts, in solution, be placed in contactwith the roots of a tree, they are absorbed, and the tree dies?

Author.-Yes; but to infer from this that there is no selection because the thing selected is not always for the good of the plant, is to lose sight of the striking analogy of our own economy. How often is the vigilance of the guardian Pylorus of the stomach eluded by mischievous agents ! yet, as nobody hesitates to recognise (in its rejection of matters that are eminently hurtful) an adaptive power in this organ, so neither is it fair to deny it in the absorbent system of plants, though they sometimes take up what is hurtful to their economy. (3.) In most European 
plants, the upper and lower surface of the leaf are separated by a single row of cells; in the Tropics, the same plants are constructed with two, three, and even four layers of these cells, by which the surface of the leaf is, of course, greatly thickened. This difference of conformation is obviously adopted by the plants to suit the respective conditions of their growth. The unsubstantial cuticle of temperate climates would not have afforded sufficient protection to the interior structure under the rays of a powerful sun; whilst the thick and fleshy leaf of the Tropics would have offered too great a resistance to the penetration of the feebler rays in colder latitudes: both are beautiful instances of adaptation. (4.) It is a curious property of many flowers to blow commonly at certain hours only; thus the Convolvulus nil blossoms at 4 A.M., the Anagallis arvensis at 8 A.M., the Dame d'onze heures (Ornithoculum umbellatum) at 11. Most fig-trees blow at 12. The Pomeridian squill flowers at 2. The Belle-de-nuit (Nyctago alapa) takes the hour of 6 for uncovering her charms, and the Convolvulus purpureus never dresses -till between 10 and 11, P.M. Now, all these flowers appear to be influenced as to the time of efflorescence by the quantity of light that each requires; and Decandolle, by varying the intensity of this agent, showed the resources which plants possess 
of accommodating themselves to circumstances. "I placed many equinoctial plants in a cave, which I had lit up with lamps during the night, and my flowers began to be deranged in their time of flowering ; opening according to the intensity of the lamplight. The Belle-de-nuit, for instance, after some days' struggle, eventually opened in the morning after a night of candlelight, and closed her petals next evening after a day during which this had been withdrawn. Some sorts of plants are not able to follow a new rule, and either do not bloom at all, or bloom irregularly." (5.) Exotic plants, when transplanted, continue for some time to flower exactly as they were wont to do in their native land; but by degrees they suit themselves to the general period of blossoming which prevails in their neighbourhood. (6.) When single flowers have, by transplantation, become double, (which occurs when there is no fruit,) they anticipate their usual period of efflorescence; and thus dahlias, since their introduction into Europe-and now that, contrary to their usual habit, they have become double-flower each year rather earlier than the year before. (7.) Mr Desfontaines has shown that plants, even in their motions, accommodate themselves to an alteration in their condition. This naturalist took some sensitive plants with him in a carriage; and observed that, so 
soon as the carriage began to roll, the plants at first trembled and drooped; but soon, accommodating themselves to the jolting, gradually began to raise their heads until the leaves had regained their usual position on the stalks. He repeated the experiment several times, and always with the same results. If the carriage, after a brief halt, went on again, the leaves would droop forthwith; but the danger of being shaken from their petioles was soon removed by the plants re-assuming the erect position, which they then continued to maintain.

Friend.-Do not certain functions of the animal economy furnish examples of a similar adaptive power?

Author.-Yes : as general instances of the adaptive power exhibited by the animal economy, we may take the Nisus formativus, that ablest ally of the surgeon, and the Vis medicatrix, to which the physician is not less indebted. This "formative effort" shows itself in the restitution of parts that have been removed, in the union of divided surfaces by the "first intention;" and sometimes in the development of a structure not usual, to suit some emergency. Thus the "Ligamentum nuche," which is strong, and wholly of a fibrous texture in rumiaating animals, who hang their heads low while they browse, in man, who bears himself erect, is usually 
replaced by cellular membrane, except only in those accustomed to bear heavy loads, where a fibrous texture replaces the cellular. The " vis medicatrix naturæ" is exhibited in a variety of ways : in one case, it enables the body to support a very high degree of temperature, by causing a perspiration to carry off the redundant heat, which else had injured it-in another, it produces a critical discharge, as in some acute diseases, and in those of which poison is the origin, sometimes eliminating it by the pores from the blood. The ability of the stomach to vomit what would be injurious to the frame if absorbed into the blood, affords so striking an instance of the operation of this same power, that an "Archæus" was once invented to preside and keep watch at the pyloric orifice. It is owing to the same power that the pupil contracts when the light is too strong for the retina, which, but for this enlargement of the iris, would be liable to injury from over-stimulation. The "Médecine expectante" of the Continent generally-counting perhaps overmuch on the constant tendency in life to re-establish such functions as have been deranged, impeded, or, for the time, suspended-trusts the issue of the disease mainly to the resources of this conservative principle; and proceeding on the known probability, that certain 
unknown resources may still remain behind, we eontinue to pronounce, in the worst forms of disease, that "While there is life there is hope."

Friend.-The instances you have hitherto given me refer mostly to parts of an animal. Can you mention some more in which the entire creature shows the same power?

Author.-Yes; many animals which have not, at a moderate temperature, the power of maintaining an independent heat, are found on some sudden emergency, when the case requires it, capable of generating a sufficient quantity of caloric to resist the deadly influence of very intense cold. Frogs will live in water frozen all round them, and, though the thermometer stand at 20 below "freezing point," keep the water in immediate contact with their bodies in a state of fluidity. If a dormouse, while hibernating, be suddenly plunged into an air much below the then low temperature of his body, his vital energies are roused into action, and his animal heat, in place of sinking, rises considerably above what it was before the experiment. If sea-fish be suddenly immersed in fresh water, they die; but, by a little precaution, the vital principle will so accommodate itself to a change of circumstances, that a cod may be made into a river-fish, and a 
river-trout become an inhabitant of the sea. The natives of the South Seas, availing themselves of the knowledge of this fact, are in the habit of driving inland, by means of narrow inlets, a variety of saltwater fish, which are prevented from regaining their natural element by an embankment of stones across the mouth of the reservoir: from these brackish preserves, the tables of their chiefs are always sure of a supply of fish.

To go from general cases to one in particular, many are the resources of this self-accommodating principle in bees ; and in no instance of its economy does it manifest itself more than in the change by which, when a hive has been bereaved of its queen, a common neuter, or operative, placed by the bees themselves in a finer cell, and fed with royal beebread, comes to transform itself, or rather to be transformed, by its vital principle, into a queen. This wonderful discovery was first made by Schirach, and it is now well-known to all bee-fanciers.

Friend.-Will you mention some other point of analogy between instinct and life?

Author.-We have seen how the same plants change their periods of flowering, or modify the structure of their leaves, to meet corresponding changes in the place to which they have been car- 
ried : so the ostrich's instinct at the Cape of Good Hope, is to incubate over her eggs during the night ; near to the equator, she leaves them to be hatched by the sun's rays alone; and, where the climate is more variable, she sits upon them during the whole twenty-four hours. Mr Knight found that a flycatcher, which built in one of the stoves, quitted its eggs whenever the thermometer was above $71^{\circ}$, and resumed her place upon the nest when the temperature sank again. Many vital phenomena, dependent on the organization of animals, become hereditary. In man, where we can best trace likenesses to parents, we see them transmitted from generation to generation; the same lineaments of face, with the same form, the same voice-nay, the very same tendency to the same diseases. Certain instincts are also hereditary ; showing how these, like those transmitted peculiarities which are visible and outward, depend also upon certain changes in the organization. Had such instincts been the result of any mental process in the animal, they could not have been transmitted to his descendents. That they are transmitted, is a matter of such notoriety that I shall content myself with quoting a single instance only. In a mongrel breed of dogs, employed by the inhabitants of the banks of the Magdalena almost 
exclusively in hunting the white-lipped peccari, a peculiar instinct has become hereditary-viz. " that of restraining their ardour, attacking no one animal in particular, but keeping the whole herd in check. These dogs, the very first time they are taken to the woods, seem acquainted with this mode of attack; whereas a dog of another breed starts forward at once, is surrounded by the peccari, and, whatever may be his strength, is speedily put to death." The instances of alterations induced in the qualities of plants by cultivation, "the taming of wild fruits," as Linnæus has correctly called it, by which they lose the thorns and prickles from their surface, are endless ; and, as in the case of the peccari dogs, become permanent by hereditary transmission.

Friend.-Is there any way of accounting for the accommodation of instinct to a variation in external circumstances?

Author-Besides the mechanical agency of outward elements on matter, living or dead, a dynamic influence on life itself must be ascribed to some of them, and more especially, perhaps, to light. Such an influence may probably be the cause of the changes in the working of the living body, or of any living organ; for any more internal ground for these changes would imply cognisance of the external change to 
which the adaptation is addressed, and consequently intelligence, or at least sensibility.

Friend.-I am to be required then, it seems, to make no legitimate distinction between life and instinct; yet, on the other hand, the expression of vital, as distinguished from instinctive acts, remains universal! I see plainly that a difference does not exist in accommodation to circumstances, for you have given me instances of that accommodation in both; nor in their seat, since both appear to reside in the inherent irritability of the organism. Neither can I oppose any essential differences in the acts themselves, since the selective power exercised by plants in feeding themselves, (as well as that of adapting themselves to climate,) appears closely to resemble the discrimination of the insect which picks its aliment from the dunghill; yet every one must make the distinction.

Author.-As to the origin of the two terms, it has been usual, I believe, to distinguish by the name of vital the partial acts of the organs of animals, and all the acts of plants ; and by that of instinctive, those which more or less regulate the conduct of the entire animal. In the first instance, nothing is performed which mere life does not seem sufficient to explain ; while in the acts reputed to be of instinct, it is so difficult, without a formal examination, to exclude 
something of the nature of mind, that it is very improbable the distinctions which you desire me to account for will ever cease. When we speak of instinct, the operation of mind as present to our mind is so certain, that, where the creature is such as to possess a doubtful reputation for being either rational or sensitive, his actions are indifferently, and without scruple, qualified by either epithet. The motions of Polypes, and the cruising about of the Medusa, the Oyster opening its shell, or the Echinus putting up its bristles, are all cases of this kind. Those who will have mind in instinct are sometimes obliged to change their opinion, and to designate the action they had hitherto considered as instinctive, by the epithet of vital. Thus the ciliæ of the Hydra, by which he makes a vortex, and draws, by so doing, his prey towards him, was once considered a purely instinctive act; but when it was found that these same ciliæ, cut off from the Hydra, made the same vortex, and acted in the same way as when they were a part of his body, physiologists changed their creed, and the motion of the ciliæ was henceforth declared to be vital. Sucking, which passes universally for an instinctive act as performed by the highest order of animals, is necessarily attended both with sensation and consciousness; yet as the same act has 
been performed by the brainless foetus, and by puppies deprived of brain, we learn from these facts that, if stripped of its accessories, even sucking is reduced to a vital act.

Friend.-Still I have an objection to urge, before I can admit with you, that an act of instinct and an act of life are essentially one and the same. You have spoken of instinct being associated with sensation in the higher animals, but you have not pretended that the vital act is in any animal so attended. You have said that sensation may or may not attend the act of sucking; but you have not said, and I suppose you will not say, that the functions of organic life are ever attended with sensation. Is not the usual presence of sensation in one case, and its universal absence in the other, a ground of distinction and difference?

Author.-I am glad you have reminded me of this, as it enables me to cite a passage from Bichat, which contains the answer you require. "There are two kinds of sensibility - one purely organic, and the other the sensibility of relation. The organic sensibility is that inherent property, by virtue of which an organ receives an impression. Thus, glands are sensible, in this sense only, to the stimulus of blood which circulates in them; and their excretory ducts re-act 
upon the fluids which they convey; so that upon this kind of sensibility depend the functions of circulation, respiration, digestion, secretion, absorption,in a word, all the functions of organic life. But the sensibility of relation is that by which our organs are not only impressionable to stimuli, but are enabled to transmit, as well as to receive, impressions to a sensorium commune. It is by this sensibility that the animal holds communion with surrounding objects; and upon it the brain and senses depend for the exercise of their respective functions. It is its peculiar province, and exclusive prerogative, to preside over external, or as it has been called, (for animals alone possesses it,) animal life-the other kind of sensibility having been imparted even to vegetable existence. Notwithstanding this distinction, however, the organic sensibility is the principle, the element, so to speak, of the sensibility of relation, and may be considered as its first grade; so that, when it augments much in an organ, it takes the character of the sensibility of relation, and the organ then earries "to the common centre certain impressions which, before, it either did not transmit, or transmitted very imperfectly." Thus you see that sensation is not more a condition of an instinctive than it is of a vital act; since, while it frequently accompanies 
instinct, it accompanies also certain pathological conditions of organs; which organs, while they were in their natural and healthy state, executed their functions without our being conscious of them.

Friend.-Well, supposing all you say to be correct, as I cannot but confess I think it is, you do not explain what has hitherto been ascribed to instinct by identifying it with life ; or you make it, after all, only an affair of words.

Author.-Either word might be used indifferently, if the word instinct was generally admitted to mean a different intensity of life, or more complex vital phenomena, for which this new name was therefore invoked; but the application of the word to particular cases, proves that it is regarded as another power, necessary to eke out the resources of the vital principle where they are held to be insufficient. Now, if instinct be neither mind nor sensation, (as I conceive myself to have offered undeniable evidence that it cannot be,) what can it be but life? and it may have been worth while to have exposed the fallacy of considering it as any thing beyond. To the philosophic and reflecting enquirer, the performance of their daily functions by his bodily organs is as profound a mystery as an insect's acts; and if he has gone along with me so far, he will not only be dis- 
posed to admit this, but will further be prepared to trace, in either case, the operation of one and the same agent :-

"Demandez à Sylva par quel sacré mystère, Ce pain, cet aliment dans ton corps digéré, Se transforme en un lait doucement préparé; Qui, toujours errant dans ses routes certaines, En longs ruisseaux de pourpre va enfler tes veines; A ton corps languissant rend un pouvoir nouveau, Fait palpiter ton cœur, et penser ton cerveau :Etonné, mais ému, il s'incline, il s'écrieDemandez-le à ce Dieu qui nous donna La Vie."

VOLTaire.

\section{F I N I S.}






